SANDIA REPORT

SAND97-1666 • UC-523

Unlimited Release

Printed July 1997

RECEIVED

AUG 011997

OSTI

\title{
Nuclear Power Plant Accident Simulations of Gasket Materials Under Simultaneous Radiation Plus Thermal Plus Mechanical Stress Conditions
}

Kenneth T. Gillen, G. Michael Malone

Prepared by

Sandia National Laboratories

Albuquerque, New Mexico 87185 and Livermore, California 94550

Sandia is a multiprogram laboratory operated by $S$ andia

Corporation, a Lockheed Martin Company, for the United states

Department of Energy under Contract DEAC04-94AL85000.

Approved for public release, distribution is thimited.

\section{1] Sandia National Laboratories}


Issued by Sandia National Laboratories, operated for the United States Department of Energy by Sandia Corporation.

NOTICE: This report was prepared as an account of work sponsored by an agency of the United States Government. Neither the United States Government nor any agency thereof, nor any of their employees, nor any of their contractors, subcontractors, or their employees, makes any warranty, express or implied, or assumes any legal liability or responsibility for the accuracy, completeness, or usefulness of any information, apparatus, product, or process disclosed, or represents that its use would not infringe privately owned rights. Reference herein to any specific commercial product, process, or service by trade name, trademark, manufacturer, or otherwise, does not necessarily constitute or imply its endorsement, recommendation, or favoring by the United States Government, any agency thereof, or any of their contractors or subcontractors. The views and opinions expressed herein do not necessarily state or reflect those of the United States Government, any agency thereof, or any of their contractors.

Printed in the United States of America. This report has been reproduced directly from the best available copy.

Available to DOE and DOE contractors from

Office of Scientific and Technical Information

P.O. Box 62

Oak Ridge, TN 37831

Prices available from (615) 576-8401, FTS 626-8401

Available to the public from

National Technical Information Service

U.S. Department of Commerce

5285 Port Royal Rd

Springfield, VA 22161

NTIS price codes

Printed copy: A03

Microfiche copy: A01 


\section{DISCLAMMER}

Portions of this document may be illegible in electronic image products. Images are produced from the best available original document. 
SAND97-1666

Distribution

Unlimited Release

Printed July, 1997

Category UC-523

\title{
NUCLEAR POWER PLANT ACCIDENT SIMULATIONS OF GASKET MATERIALS UNDER SIMULTANEOUS RADIATION PLUS THERMAL PLUS MECHANICAL STRESS CONDITIONS
}

\author{
Kenneth T. Gillen and G. Michael Malone \\ Materials Aging and Reliability: Bulk Properties Department \\ Sandia National Laboratories \\ P. O. Box 5800 \\ Albuquerque, NM 89185-1407 USA
}

\begin{abstract}
In order to probe the response of silicone door gasket materials to a postulated severe accident in an Italian nuclear power plant, compression stress relaxation (CSR) and compression set (CS) measurements were conducted under combined radiation (approximately $6 \mathrm{kGy} / \mathrm{h}$ ) and temperature (up to $230^{\circ} \mathrm{C}$ ) conditions. By making some reasonable initial assumptions, simplified constant temperature and dose rates were derived that should do a reasonable job of simulating the complex environments for worst-case severe events that combine overall aging plus accidents. Further simplification coupled with thermal-only experiments allowed us to derive thermal-only conditions that can be used to achieve CSR and CS responses similar to those expected from the combined environments that are more difficult to simulate. Although the thermal-only simulations should lead to sealing forces similar to those expected during a severe accident, modulus and density results indicate that significant differences in underlying chemistry are expected for the thermal-only and the combined environment simulations.
\end{abstract}




\section{ACKNOWLEDGMENTS}

The author wishes to thank Christine White for the density measurements, and Paolo Vanini of ENEL for many useful communications and comments. Sandia is a multiprogram laboratory operated by Sandia Corporation, a Lockheed Martin Company, for the United States Department of Energy under Contract DE-AC04-94AL85000. 


\section{CONTENTS}

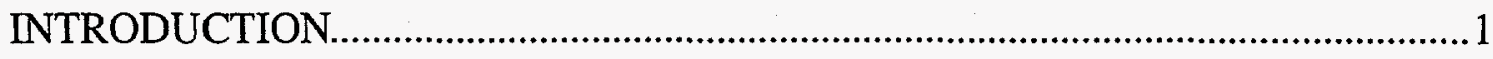

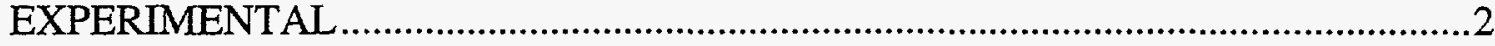

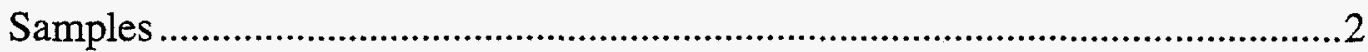

Radiation aging procedures..........................................................................

Compression stress relaxation and compression set measurements ....................... 3

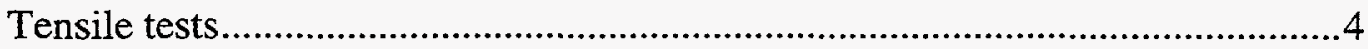

Density measurements ..........................................................................................

Modulus profiles ..................................................................................................4

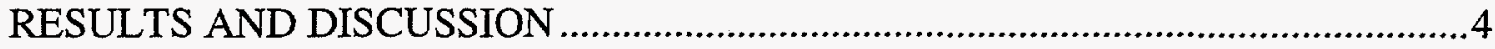

Compression stress relaxation and compression set results...................................

CSR and CS results in combined radiation plus thermal environments ................6

CS results in thermal-only environments.............................................................

Elongation results................................................................................................. 10

Importance of diffusion-limited oxidation (DLO)- theoretical estimate................10

Importance of DLO- experimental measurements using modulus profiling..........11

Density results........................................................................................... 12

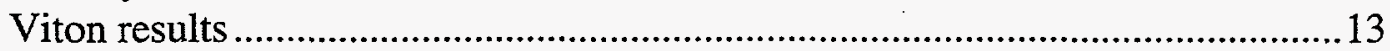

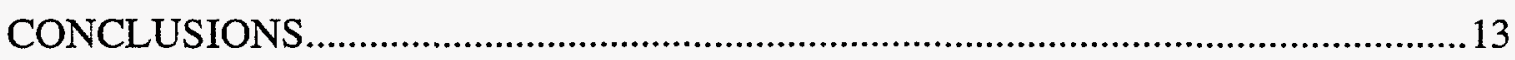

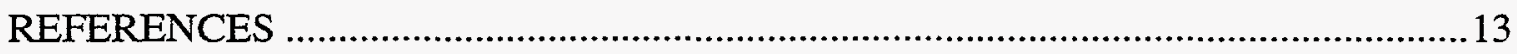

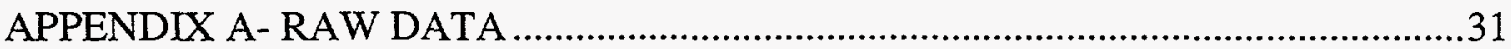

\section{FIGURES}

1 Temperature profile for Italian Severe Accident SA-1 ……....................................15

2 Temperature profile for Italian Severe Accident SA-2 …...........................................15

3 Time-dependent force plots for Experiment C65MCC-1 .................................................16

4 Fig. 3 results after putting CSR aging jig in aging......................................................16

5 Normalized CSR results for the MCC material .......................................................... 17

6 Normalized CSR results for the M material .........................................................17

7 Superposition of the high-temperature results from Figs. 5 and $6 \ldots \ldots \ldots \ldots \ldots \ldots \ldots \ldots \ldots \ldots \ldots . . .18$

8 CSR results predicted for the MCC material to simulate SA-1 and SA-2 .....................18

9 CSR results predicted for the M material to simulate SA-1 and SA-2 ….......................19

10 Superposition of high-temperature combined environment CS results .........................19

11 CS results predicted for the MCC material to simulate SA-1 and SA-2 ….................20

$12 \mathrm{CS}$ results predicted for the $\mathrm{M}$ material to simulate SA-1 and SA-2 …........................20

13 Italian and U. S. CS results for the MCC material in thermal-only environments ......21

14 Time-temperature superposition of the thermal-only CS data from Fig. 13................21

15 Arrhenius plot of the empirical shift factors used in Fig. $14 \ldots \ldots \ldots \ldots \ldots \ldots \ldots \ldots \ldots \ldots \ldots \ldots . . .22$

16 Selection of thermal-only conditions for MCC to best simulate SA-1 ….....................22

17 Italian and U. S. CS results for the $M$ material in thermal-only environments............23

18 Time-temperature superposition of the thermal-only CS data from Fig. 17...............22

19 Arrhenius plot of the empirical shift factors used in Fig. 18 .......................................24

20 Selection of thermal-only conditions for $\mathrm{M}$ to best simulate SA-1 ….........................24 
21 Correlation of CSR and CS results for both MCC and M materials............................25

22 Thermal-only CSR results (MCC) versus predictions from Figs. 14 and 21...............25

23 Transformed CSR result for $234^{\circ} \mathrm{C}$ versus result predicted to simulate SA-1 ............26

24 Superposition of MCC combined environment normalized tensile elongation data ...26

25 Superposition of $M$ combined environment normalized tensile elongation ................27

26 Superposition of MCC thermal-only normalized tensile elongation data.....................27

27 Superposition of $\mathbf{M}$ thermal-only normalized tensile elongation data...........................28

28 Modulus profile results for $\sim 2 \mathrm{~mm}$ thick MCC tensile specimens ...............................28

29 Modulus profile results of CSR and tensile M specimens .........................................29

30 Density results for MCC tensile samples...................................................................29

$31 \mathrm{CSR}$ and CS results for the Viton V747 material aged at $230^{\circ} \mathrm{C}$ plus $5.55 \mathrm{kGy} / \mathrm{h}$.......30

\section{TABLES}

1 Constant temperature equivalent to SA-1 and SA-2 profiles..........................................

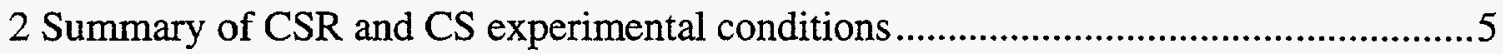

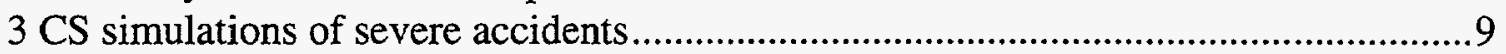

A-1 Data used to obtain CSR and CS Results for Experiment C65MCC-1 ......................31

A-2 Data used to obtain CSR and CS Results for Experiment C65MCC-2 …...................31

A-3 Data used to obtain CSR and CS Results for Experiment C65MCC-3 …...................31

A-4 Data used to obtain CSR and CS Results for Experiment C65MCC-4 …..................32

A-5 Data used to obtain CSR and CS Results for Experiment C65MCC-5 …..................32

A-6 Data used to obtain CSR and CS Results for Experiment C65M-1 ….......................32

A-7 Data used to obtain CSR and CS Results for Experiment C65M-2 …........................33

A-8 Data used to obtain CSR and CS Results for Experiment C65M-3 ...........................33

A-9 Data used to obtain CSR and CS Results for Experiment C65M-4 ..........................33

A-10 Data used to obtain CSR and CS Results for Experiment C65M-5 ….....................34

A-11 Data used to obtain CSR and CS Results for Experiment V747-75-1 ....................34

A-12 Italian CS data (\% set) for Oven-Aging of MCC at 20\% Compression ....................35

A-13 Italian CS data (\% set) for Oven-Aging of $\mathrm{M}$ at 20\% Compression .........................35

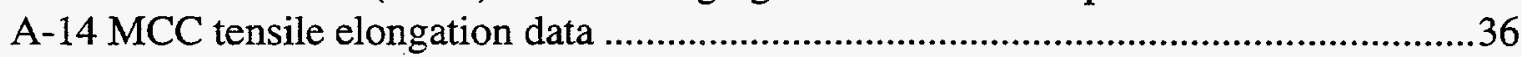

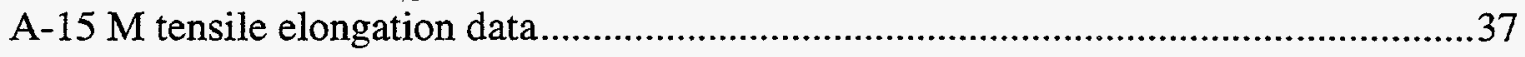




\section{INTRODUCTION}

This report summarizes the Sandia portion of a cooperative program involving studies of silicone gasket materials supplied by the Italian National Electric Power Authority, Ente Nazionale per l'Energia Elettrica (ENEL). These materials are being considered for door seals in Italian nuclear reactors and are required to withstand lifetime aging as well as postulated accident conditions. The latter would involve simultaneous environments of mechanical strain, steam, high dose-rate radiation and high temperatures. ENEL is planning to conduct an aging plus accident simulation on a full-sized seal installed on an actual door. Given the large size of the experimental arrangement, they would like to utilize an approximately two-week duration, thermal-only simulation of both the aging and accident environments. Because of Sandia's expertise in combined radiation plus thermal aging effects [1-4] and our unique experimental facilities, they requested that we analyze and experimentally determine the effects of the complex combined environments on their silicone materials. Their hope was that we might be able to show that it is possible to simulate both the aging environments and the predicted combined radiation plus thermal plus steam accident environments on a mechanically stressed silicone gasket using the thermal-only environment planned for their full-scale door seal tests. The major goal of our work was therefore to determine if a thermal-only simulation could be shown to be reasonably equivalent to the expected combined aging plus accident scenario.

Given the limited funding available for the studies and the complex aging and accident scenarios envisioned for the gasket materials, it was necessary immediately to simplify the experimental plans by making a number of reasonable assumptions. Based on Italian input, we estimate that the total aging plus accident dose is $\sim 450 \mathrm{kGy}$ of gamma plus $\sim 300 \mathrm{kGy}$ of beta, most of which is due to the accident. We chose to ignore the effects of the low penetrating beta contribution, since beta particles should have little effect on the metal-to-metal sealed gasket. We also decided to eliminate the normal aging environments from the studies. This was done since the total radiation dose during normal lifetime nuclear plant operation is a minor part of the $450 \mathrm{kGy}$ total dose and since the normal aging temperature will have an insignificant effect on thermally robust silicone materials. Since it was cost-prohibitive to include steam during our simulations and evidence from our earlier loss of coolant accident (LOCA) simulation studies in France indicates that steam has little effect on radiation-aged and thermally aged silicone materials [5], we also concluded that steam during the accident simulation was unlikely to have an important effect and therefore ignored this environment in our current studies. Finally, to simplify the combined environment simulations, we carried out all of our simulations under constant dose-rate and temperature conditions, even though dose rates and temperatures will vary during the predicted severe accidents.

Figures 1 and 2 show two predicted temperature histories for Italian severe accidents (SA-1 and SA-2, respectively). SA-1 lasts a total of $80 \mathrm{~h}$ and SA-2 a total of $60 \mathrm{~h}$. This turns out to be convenient since our highest available radiation dose rate $(\sim 6 \mathrm{kGy} / \mathrm{h})$ requires $\sim 75 \mathrm{~h}$ to reach the desired overall gamma dose of $450 \mathrm{kGy}$. Therefore, we focused our initial experimental studies on attempting to determine the equivalent 
constant temperature needed over a 75 -h combined exposure $(6 \mathrm{kGy} / \mathrm{h}$ plus temperature) that would give thermal conditions equivalent to the time-temperature histories in Figs. 1 and 2. The equivalent temperature (one for SA-1, a second for SA-2) will depend upon the Arrhenius activation energy for the combined environment exposures (i.e., on how the degradation at a constant dose-rate of $6 \mathrm{kGy} / \mathrm{h}$ depends on temperature for temperatures close to those seen during the predicted accident). Since this activation energy would be unknown until combined environment studies were completed, we used two initial values for planning purposes. These were 10 and $20 \mathrm{kcal} / \mathrm{mol}$, values that we felt would probably bracket the actual value. The procedure therefore was to estimate the constant temperature value which, if applied for $75 \mathrm{~h}$, would be equivalent to the complex thermal profiles shown in Figs. 1 and 2 . The results are summarized in Table 1.

Table 1. Constant temperature equivalent to SA-1 and SA-2 profiles

\begin{tabular}{ccc}
\hline $\begin{array}{c}\text { Accident temp. } \\
\text { Profile }\end{array}$ & $\begin{array}{c}\text { Equivalent constant temperature for } 75 \mathrm{~h} \text { exposure (Arrhenius model) } \\
\text { (for } 10 \mathrm{kcal} / \mathrm{mol} \text { ) }\end{array}$ & (for $20 \mathrm{kcal} / \mathrm{mol}$ ) \\
\hline SA-1 (Fig. 1) & $181^{\circ} \mathrm{C}$ & $201^{\circ} \mathrm{C}$ \\
SA-2 (Fig. 2) & $205^{\circ} \mathrm{C}$ & $218^{\circ} \mathrm{C}$ \\
\hline
\end{tabular}

Based on these results, we decided to carry out combined environment aging experiments at $\sim 6 \mathrm{kGy} / \mathrm{h}$ plus $200^{\circ} \mathrm{C}$ and at $\sim 6 \mathrm{kGy} / \mathrm{h}$ plus $230^{\circ} \mathrm{C}$; the results would allow us to estimate the actual combined environment activation energies for the rnaterials studied and to determine the precise constant combined environment conditions necessary to best simulate SA-1 and SA-2. We could then use the results from the two actual combined environment exposures $\left(6 \mathrm{kGy} / \mathrm{h}\right.$ plus $200^{\circ} \mathrm{C}$ and $6 \mathrm{kGy} / \mathrm{h}$ plus $\left.230^{\circ} \mathrm{C}\right)$ to interpolate or extrapolate slightly to make predictions for the conditions that best simulate SA-1 and SA-2. The plan was then to see if thermal-only conditions could be found that would give degradation behavior over a two week period that was reasonably equivalent to the degradation behavior predicted for combined environment simulations of the two severe accidents.

\section{EXPERIMENTAL}

\section{$\underline{\text { Samples }}$}

The silicone samples used for the study were supplied by ENEL as compression-molded buttons ( $29 \mathrm{~mm}$ diameter by $\sim 12.6 \mathrm{~mm}$ thickness) used for the compression stress relaxation (CSR) and compression set (CS) experiments, and as compression-molded sheets ( $\sim \mathrm{mm}$ by $150 \mathrm{~mm}$ by $2 \mathrm{~mm}$ thick) used for the tensile tests. Two different silicones were supplied, the first was designated compound C65MCC/60 (which will be abbreviated to MCC from now on) and the second was C65M/60 (abbreviated to M). A typical Viton (registered trademark of E. I. du Pont De Nemours) gasket material was 
procured as a compression molded sheet (compound V747-75) from Parker Seal Company (dimensions $\sim 150 \mathrm{~mm}$ by $150 \mathrm{~mm}$ by $1.5 \mathrm{~mm}$ thick). Three 12.5 -mm-diameter disks were cut from the sheet and stacked together (total thickness $4.42 \mathrm{~mm}$ ) for use in a compression stress relaxation screening study at $230^{\circ} \mathrm{C}$ plus $\sim 6 \mathrm{krad} / \mathrm{h}$ to compare Viton degradation behavior with the silicone materials.

\section{$\underline{\text { Radiation aging procedures }}$}

Radiation aging was carried out in the highest dose rate position of Sandia's Low Intensity Cobalt Array (LICA) facility, which has been described in detail in previous publications [6]. The facility has water-tight aging cans that are lowered $\sim 5 \mathrm{~m}$ under water to a cobalt- 60 irradiation area. Since aging at $230^{\circ} \mathrm{C}$ was required for the current experiments and the aging cans were previously limited to $-150^{\circ} \mathrm{C}$, one aging can was modified to allow long-term aging at up to $\sim 250^{\circ} \mathrm{C}$. The temperature-controlled interior of this can had a maximum available sample region measuring $\sim 10 \mathrm{~cm}$ diameter by $\sim 18$ $\mathrm{cm}$ length. At $250^{\circ} \mathrm{C}$, the temperature variation was measured to be $\pm 2^{\circ} \mathrm{C}$ across this sample region. The sample region was just large enough to contain two compression set fixtures (described below), used for the compression stress relaxation and compression set experiments, and the required number of tensile samples. Since the CS fixtures contained sufficient metal to cause some attenuation of the gamma rays at the samples, TLDs were placed in the center of the fixtures to measure the radiation dose rate during the experiments. Dose rates were estimated to be $6 \mathrm{kGy} / \mathrm{h} \pm 10 \%$ for the early experiments, dropping to $-5.5 \mathrm{kGy} / \mathrm{h}$ for the final experiments due to the decay of the cobalt-60 during the course of the studies. Air was continuously circulated through the sample region during the aging experiments at a flow rate of $\sim 200 \mathrm{~cm}^{3} / \mathrm{min}$.

\section{Compression stress relaxation and compression set measurements}

Compression stress relaxation measurements were made using a Shawbury- Wallace Compression Stress Relaxometer MK II. This instrument uses special Shawbury-Wallace jigs (CSR jigs) to compress and age cylindrical samples at elevated temperature; the jigs are periodically removed from the aging oven. After allowing the jigs to equilibrate at room temperature, a sealing force measurement was made and then the jigs were returned to the oven for further aging. Since the CSR jigs were not designed to withstand the severe environments used for the current accident simulations $(6 \mathrm{kGy} / \mathrm{h}$ at temperatures up to $230^{\circ} \mathrm{C}$ ), we utilized typical compression set fixtures [7] to compress and age the materials. At selected intervals during the aging, the LICA aging can was removed from the aging environment and the two CS fixtures containing identical samples were quickly removed. One of the two fixtures was allowed to cool to room temperature with its sample kept under compression; the second fixture was immediately opened, its silicone disk removed and placed on a wood surface for $\sim 30$ minutes, after which its thickness was measured to obtain an estimate of compression set. This sample was next placed in one of the CSR jigs and compressed to the identical thickness utilized in the CS fixture and then allowed to sit at room temperature for a minimum of $12 \mathrm{~h}$. 
The first sample, which was never removed from its CS fixture, was also allowed to sit at room temperature for a minimum of $12 \mathrm{~h}$, after which it was quickly removed from its CS fixture and transferred to another of the CSR jigs and compressed to the identical thickness utilized in the CS fixture. After waiting at least another hour, the room temperature force was obtained for both samples. Both samples were then quickly transferred back to the CS fixtures for further aging in the LICA facility. By repeating this procedure at several time intervals, it was possible to obtain compression stress relaxation and compression set values versus aging time. Although the data sampling procedures were somewhat different, the scatter in the compression stress relaxation results from the two samples was similar to that found for identical samples run using the standard CSR procedure.

\section{Tensile tests}

Tensile samples ( $150 \mathrm{~mm}$ long by $6 \mathrm{~mm}$ wide) were cut from the compression-molded sheets before aging. Tensile testing $(5.1-\mathrm{cm}$ initial jaw separation, $12.7 \mathrm{~cm} / \mathrm{min}$ strain rate) was performed on an Instron 1000 tensile testing machine equipped with pneumatic grips and an extensometer clamped on the sample.

\section{Density measurements}

Density measurements were made using the Archimedes approach, in which the sample (typically $20 \mathrm{mg}$ ) is weighed in air and then in ethanol. A minimum of 3 samples of each material were measured and the average density recorded.

\section{Modulus profiles}

Modulus measurements were made using a computer-controlled, automated version of our modulus profiling apparatus, which has been described in detail previously [8-10].

\section{RESULTS AND DISCUSSION}

\section{Compression stress relaxation and compression set experimental results}

Table 2 lists the experimental conditions (radiation dose rate, temperature, and mechanical strain) for the $11 \mathrm{CSR}$ and CS experiments. The five experiments on the C65MCC sample are designated C65MCC-1, C65MCC-2, etc., with similar designations for the five experiments on the $\mathrm{C} 65 \mathrm{M}$ material. The experimental procedure was to initially strain each sample in the special CSR jigs under room temperature $\left(\sim 23^{\circ} \mathrm{C}\right)$. This was followed by a measurement of the sealing force as quickly as possible (typically within $30 \mathrm{~s}$ of straining the sample), followed by a second measurement after $\sim 10 \mathrm{~min}$. The CSR jigs were then kept at room temperature (no radiation) for $\sim 20 \mathrm{~h}$, at which time a third force measurement was made. The initial decay in force over the first $\sim 20 \mathrm{~h}$ represented purely physical relaxation processes (completely reversible); this decay was 
found to be $\sim 12 \pm 1 \%$ for the MCC material and $16 \pm 1 \%$ for the M material. After the room temperature measurements were completed, the CSR jigs were quickly opened, and the samples removed and transferred to the CS fixtures at the same sample strain as used for the CSR jigs. The CS fixtures were then placed in the aging environment for the first time and the procedures described in the experimental section above were used. Normally two samples were run under identical conditions for each experimental condition (only two CS fixtures could be fitted in the specially modified, hightemperature LICA aging can).

Table 2. Summary of CSR and CS experimental conditions

\begin{tabular}{ccccc}
\hline Experiment & $\begin{array}{c}\text { Dose Rate, } \\
\mathrm{kGy} / \mathrm{h}\end{array}$ & $\begin{array}{c}\text { Aging Temper- } \\
\text { ature, }{ }^{\circ} \mathrm{C}\end{array}$ & $\begin{array}{c}\text { Compressed sample } \\
\text { thickness, mm }\end{array}$ & $\begin{array}{c}\text { Approx. Sample } \\
\text { strain, \% }\end{array}$ \\
\hline C65MCC-1 & 5.94 & 230 & 8.89 & 29 \\
C65MCC-2 & 0 & 230 & 8.89 & 29 \\
C65MCC-3 & 5.88 & 200 & 9.55 & 24 \\
C65MCC-4 & 0 & 200 & 9.55 & 24 \\
C65MCC-5 & 5.80 & 45 & 9.55 & 24 \\
C65M-1 & 5.91 & 230 & 9.55 & 24 \\
C65M-2 & 0 & 230 & 9.55 & 24 \\
C65M-3 & 5.71 & 200 & 9.55 & 24 \\
C65M-4 & 0 & 200 & 9.55 & 24 \\
C65M-5 & 5.64 & 45 & 9.55 & 24 \\
v747-75-1 & 5.55 & 230 & 3.28 & 26 \\
\hline
\end{tabular}

Figure 3 shows a plot of the force for the two MCC samples aged at $230^{\circ} \mathrm{C}$ plus 5.94 $\mathrm{kGy} / \mathrm{h}$ (experiment C65MCC-1). The slow drop in force over the first $18 \mathrm{~h}$ represents the $12 \%$ physical relaxation drop occurring at room temperature; at this point, the samples were transferred to the combined $230^{\circ} \mathrm{C}$ plus $5.94 \mathrm{kGy} / \mathrm{h}$ environment, where the drop in force became much faster due to chemical degradation. The results plotted in Fig. 3 are also tabulated in Table A-1 of Appendix A. Since the important aging time was the time that the CS fixture was aged in the aging environment, time zero in Table A-1 is set to the time at which the CS fixture is first placed in the aging environment. Therefore, the negative times listed refer to the experimental times during which physical relaxation occurred at room temperature (i.e., the first force measurement at room temperature is defined as taking place at $-18 \mathrm{~h}$ ). Since we are interested primarily in the chemical degradation effects caused by radiation and high temperatures, we will confine all of our subsequent analyses to the times in the aging environments. Using this approach, Fig. 4 shows the results from Fig. 3 replotted starting at the time the samples were first placed at $230^{\circ} \mathrm{C}$ plus $5.94 \mathrm{kGy} / \mathrm{h}$. Tables A-2 through A- 11 in Appendix A give the raw data for the other 10 experimental conditions. The final column in Tables A-1 through A-11 lists the experimental thickness results, which can be used together with the strain results in Table 2 to obtain compression set results. 


\section{CSR and CS results in combined radiation plus thermal environments}

Figures 5 and 6 show the compression stress relaxation results for the two silicone materials under the three combined environment conditions. The results are plotted as the force normalized to the initial room temperature force measurement and come from Tables A-1, A-3, A-5, A- $6, \mathrm{~A}-8$ and A- 10 . At $200^{\circ} \mathrm{C}$ and $230^{\circ} \mathrm{C}$, the results indicate that the MCC material lasts approximately twice as long as the M compound. Since the shapes of the high-temperature results are similar when plotted against log of the aging time, time-temperature superposition procedures $[2,3]$ can be used to determine the experimental multiplicative shift factor, usually referred to as $a_{T}$, relating the two temperatures. It turns out for both materials that an $a_{T}$ equal to 0.53 achieves excellent time-temperature superposition, as evidenced by the results shown in Fig. 7, where both sets of data are shifted to a reference temperature of $230^{\circ} \mathrm{C}$. Since a shift factor of 0.53 corresponds to an Arrhenius activation energy of $\sim 10 \mathrm{kcal} / \mathrm{mol}$, this result can now be used to determine the effective constant temperature needed to simulate the severe accident scenarios shown in Figs. 1 and 2. As indicated in Table 1, SA-1 can now be taken as equivalent to $\sim 75 \mathrm{~h}$ at $181^{\circ} \mathrm{C}$ and SA-2 as equivalent to $\sim 75 \mathrm{~h}$ at $205^{\circ} \mathrm{C}$. Thus a reasonable simulation of SA-1 would require $75 \mathrm{~h}$ in a combined environment of $181^{\circ} \mathrm{C}$ plus $6 \mathrm{kGy} / \mathrm{h}$, whereas SA-2 would require $75 \mathrm{~h}$ in a combined environment of $205^{\circ} \mathrm{C}$ plus $6 \mathrm{kGy} / \mathrm{h}$. We can use the superposed combined environment results at $230^{\circ} \mathrm{C}$ from Fig. 7 plus the $10 \mathrm{kcal} / \mathrm{mol}$ activation energy to predict the compression stress relaxation results under these combined radiation and thermal exposures for the two compounds. The predicted results for MCC are shown in Fig. 8; those for M are given in Fig. 9.

CS results were calculated [7] from the same experiments, although less data were obtained since sample thickness measurements were taken on only one of the two samples aged at each experimental condition (see the last columns in Tables A-1, A-3, A6 and A-8). These CS data, calculated from the thickness measurements coupled with the compressed sample thicknesses in Table 2, can be analyzed in a similar fashion to the CSR results. Figure 10 shows the superposition results for both samples after the hightemperature, combined environment aging. The superposition for the MCC sample uses a shift factor of 0.50 , corresponding to an $\sim 11 \mathrm{kcal} / \mathrm{mol}$ activation energy; for the $\mathrm{M}$ sample, a shift factor of 0.57 is used, corresponding to $\sim 9 \mathrm{kcal} / \mathrm{mol}$. Even though these results are derived with less data than the CSR results, their activation energies are in essential agreement with the $10 \mathrm{kcal} / \mathrm{mol}$ CSR estimates. We will therefore assume a 10 $\mathrm{kcal} / \mathrm{mol}$ value for the CS results for both samples. This leads, in a manner analogous to the reasoning leading to Figs. 8 and 9, to predictions for the CS results under conditions corresponding to the two severe accident scenarios SA-1 and SA-2. The results are shown in Figs. 11 and 12.

Although steam has been eliminated from consideration and the complex severe accident time dependencies of both the radiation and temperature environments have been replaced by time-independent equivalent exposures, the results shown in Figs. 8, 9, 11, and 12 should closely represent the material responses expected under the two accident 
scenarios. Given these results and the need to survive for $\sim 75 \mathrm{~h}$, it is immediately clear that severe degradation is predicted to occur for the M material in both SA-1 and SA-2, whereas the MCC material may still have some properties remaining, especially for the SA-1 environment. Even when the force is predicted to reach zero and the CS is predicted to reach $100 \%$ before the end of the accident, it must be kept in mind that the seals may still perform adequately during the accident. One reason is that all of our CSR and CS measurements were made at room temperature, whereas the seal is required to seal at the elevated temperatures appropriate to SA-1 and SA-2. When the temperature is dropped from the high temperatures used during degradation to room temperature for the property measurements, shrinkage of the material will cause the compression set to be higher than that at elevated temperatures and the force to be lower. These effects could be accounted for by measuring the modulus and coefficient of expansion of aged samples and using these results to transform the room temperature results back up to elevated temperatures. Such measurements are being made by ENEL as part of their effort.

\section{CS results in thermal-only environments}

Once the predicted results in Figs. 8, 9, 11 and 12 were derived, one of the important goals of this project was to determine whether two-week long, thermal-only exposures on compressed seals could be used to simulate the results expected from combined radiation plus thermal environments on compressed seals. In other words, can thermal-only environments be found that cause damage that is reasonably equivalent to that predicted to occur in the combined environments. If such conditions can be found, they can then be slowed down by $\sim 4.5$ times $(=336 \mathrm{~h} / 75 \mathrm{~h}$ ) by using a lower temperature exposure to achieve the goal of a two week thermal exposure.

Although we carried out some limited CSR and CS measurements in thermal-only environments of $230^{\circ} \mathrm{C}$ and $200^{\circ} \mathrm{C}$ (see Tables A-2, A-4, A-6 and A-8), a much larger effort was devoted to thermal-only CS measurements by ENEL, which carried out more extensive experiments at five temperatures $\left(170^{\circ} \mathrm{C}, 180^{\circ} \mathrm{C}, 190^{\circ} \mathrm{C}, 200^{\circ} \mathrm{C}\right.$ and $\left.220^{\circ} \mathrm{C}\right)$ and two compressive strain levels (10\% and 20\%). Tables A-12 and A-13 summarize the ENEL results for $20 \%$ compression for the MCC and M materials, respectively. Given the much larger CS data set available (relative to the CSR results) for thermal-only aging, we first analyze both the US and Italian thermal-only CS data and compare the responses with the combined-environment CS predictions given in Figs. 11 and 12. We then show that a reasonable correlation exists between CS and CSR data (which is not unexpected), which will allow us to transform the thermal-only CS predictions to thermal-only CSR predictions for comparison with the predicted results given in Figs. 8 and 9.

Figure 13 summarizes the Italian CS results for $20 \%$ compression at five temperatures (Tables A-12 and A-13) plus the US results for $24 \%$ compression at two temperatures (Tables A-2 and A-4) for the MCC material. At the only temperature common to both studies $\left(200^{\circ} \mathrm{C}\right)$, the agreement between Italian and US data is excellent. The results shown in Fig. 13 are empirically time-temperature superposed at a reference temperature of $230^{\circ} \mathrm{C}$ in Fig. 14. Since scatter in compression set values should be much larger at low 
set values, where physical (reversible) effects are much more important, the analysis focused on optimizing the superposition above $\sim 50 \%$ set, where the chemical (irreversible) effects dominate. The empirical multiplicative shift factors $a_{T}$ (one for each experimental temperature) used to achieve the superposition are plotted in an Arrhenius plot (log $a_{T}$ versus inverse absolute temperature) in Fig. 15. For Arrhenius behavior, the predicted relationship between the empirical shift factors and the inverse absolute temperature $T$ is given by [1-4]

$$
a_{T}=\exp \left[\frac{E_{a}}{R}\left(T_{\text {ref }}^{-1}-T^{-1}\right)\right]
$$

where $R$ is the gas constant, $E_{a}$ is the Arrhenius activation energy, and $T_{\text {ref }}$ is the absolute reference temperature $\left(503 \mathrm{~K}=230^{\circ} \mathrm{C}\right.$ for the present data). The results shown in Fig. 15 are consistent with Arrhenius behavior and indicate that an Arrhenius $E_{a}$ of $\sim 29 \mathrm{kcal} / \mathrm{mol}$ describes the thermal aging of the MCC material.

We can now shift the $230^{\circ} \mathrm{C}$ thermal-only superposed compression set data of Fig. 14 to higher temperatures in order to try and match the predicted combined environment results appropriate to the MCC material for the 75-h severe accidents, SA-1 and SA-2 (given in Fig. 11). For instance, to get the closest match to the SA-1 curve in Fig. 11, the results from Fig. 14 must be multiplied by $\sim 0.8$, which, for the thermal activation energy of 29 $\mathrm{kcal} / \mathrm{mol}$, corresponds to a temperature increase from $230^{\circ} \mathrm{C}$ to $234^{\circ} \mathrm{C}$. Figure 16 shows the result, which indicates that from a strictly compression set point of view, a $234^{\circ} \mathrm{C}$ thermal-only environment for $75 \mathrm{~h}$ does a reasonable job of simulating the 75 -h combined environment found to approximate the SA-1 severe accident. If a two-week thermal-only simulation is required, the degradation would need to be slowed down by $\sim 4.5$ times. With the $29 \mathrm{kcal} / \mathrm{mol}$ activation energy, this implies a two-week exposure to $209^{\circ} \mathrm{C}$. Similar analyses can be done to show that a 75 -h exposure to $244^{\circ} \mathrm{C}$ or a two-week exposure to $218^{\circ} \mathrm{C}$ will simulate the $75-\mathrm{h} \mathrm{SA}-2$ curve from Fig. 11.

Figure 17 summarizes the Italian CS results for $20 \%$ compression at five temperatures plus the US results for $24 \%$ compression at two temperatures for the $\mathrm{M}$ material. At the only temperature common to both studies $\left(200^{\circ} \mathrm{C}\right)$, the agreement between Italian and US data is excellent. The results shown in Fig. 17 are empirically time-temperature superposed in Fig. 18. Since scatter in compression set values should be much larger at low set values where physical (reversible) effects are much more important, the analysis focused on optimizing the superposition above $\sim 50 \%$ set, where the chemical (irreversible) effects dominate. The empirical shift factors used to achieve the superposition are plotted in an Arrhenius plot ( $\log a_{T}$ versus inverse absolute temperature) in Fig. 19. The results indicate that an Arrhenius $E_{a}$ of $\sim 17 \mathrm{kcal} / \mathrm{mol}$ describes the thermal aging of the $\mathrm{M}$ material, which is very different from the $29 \mathrm{kcal} / \mathrm{mol}$ found for the MCC material. 
We can now shift the $230^{\circ} \mathrm{C}$, thermal-only, superposed compression set data of Fig. 18 to higher temperatures in order to try and match the predicted combined environment results for the $\mathrm{M}$ material appropriate to the 75-h severe accidents, SA-1 and SA-2 (given in Fig. 12). For instance, to get the closest match to the SA-1 curve in Fig. 12, the results from Fig. 18 must be multiplied by $\sim 0.63$, which for the thermal activation energy of 17 $\mathrm{kcal} / \mathrm{mol}$, corresponds to a temperature increase from $230^{\circ} \mathrm{C}$ to $244^{\circ} \mathrm{C}$. Figure 20 shows the result, which indicates that from a strictly compression set point of view, a $244^{\circ} \mathrm{C}$ thermal-only environment for $75 \mathrm{~h}$ does an excellent job of simulating the 75 -h combined environment found to approximate the SA-1 severe accident. If a two-week thermal-only simulation is required, the degradation would need to be slowed down by $\sim 4.5$ times. With the $17 \mathrm{kcal} / \mathrm{mol}$ activation energy, this implies a two week exposure to $201^{\circ} \mathrm{C}$. Similar analyses can be done to show that a $75-\mathrm{h}$ exposure to $262^{\circ} \mathrm{C}$ or a two week exposure to $216^{\circ} \mathrm{C}$ will simulate the 75 -h SA-2 curve from Fig. 12. Table 3 summarizes the above results.

Table 3. CS simulations of severe accidents

\begin{tabular}{ccccc}
\hline Accident & Material & $\begin{array}{c}75 \mathrm{hr} \mathrm{R}+\mathrm{T} \\
\text { Conditions }\end{array}$ & $\begin{array}{c}75 \mathrm{hr} \text { T-only } \\
\text { Conditions }\end{array}$ & $\begin{array}{c}2 \text { week T-only } \\
\text { Conditions }\end{array}$ \\
\hline SA-1 & MCC & $181^{\circ} \mathrm{C}+6 \mathrm{kGy} / \mathrm{h}$ & $234^{\circ} \mathrm{C}$ & $209^{\circ} \mathrm{C}$ \\
SA-1 & $M$ & $181^{\circ} \mathrm{C}+6 \mathrm{kGy} / \mathrm{h}$ & $244^{\circ} \mathrm{C}$ & $201{ }^{\circ} \mathrm{C}$ \\
SA-2 & MCC & $205^{\circ} \mathrm{C}+6 \mathrm{kGy} / \mathrm{h}$ & $244^{\circ} \mathrm{C}$ & $218^{\circ} \mathrm{C}$ \\
SA-2 & $M$ & $205^{\circ} \mathrm{C}+6 \mathrm{kGy} / \mathrm{h}$ & $262^{\circ} \mathrm{C}$ & $216^{\circ} \mathrm{C}$ \\
\hline
\end{tabular}

The relationship between CSR and CS results for all of the high-temperature experiments both with and without radiation are shown in Fig. 21 , where $F / F_{0}$ represents the CSR force divided by its force at time zero. To a reasonable first approximation, all of the results fall on a universal curve which is drawn through the data. This correlation between the two types of data, and the fact that the force approaches zero as the CS values approach $100 \%$, should be expected. The curve through the data allows us to transform CS data to CSR data and vice versa. For instance, we take the superposed curve through the $\mathrm{CS}$ results at $230^{\circ} \mathrm{C}$ for the MCC material (Fig. 14) and utilize the transform curve from Fig. 21 to predict $F / F_{0}$ results at $230^{\circ} \mathrm{C}$ and (with the known activation energy of $29 \mathrm{kcal} / \mathrm{mol}$ ) at $200^{\circ} \mathrm{C}$. These curves are plotted in Fig. 22, together with the actual CSR data from Tables A-2 and A-4. The predictions from the transformations are in reasonable agreement (shape of curve, temperature dependence, magnitude) with the experimental results. From the CS results in Table 3, we concluded that $234^{\circ} \mathrm{C}$ for $75 \mathrm{~h}$ for the MCC material is equivalent to $181^{\circ} \mathrm{C}$ plus $6 \mathrm{kGy} / \mathrm{h}$ for $75 \mathrm{~h}$. If we now compare the transform results for CSR at $234^{\circ} \mathrm{C}$ with the predicted combined environment CSR result from Fig. 8, we again see reasonable agreement (Fig. 23), especially in the critically important later stages of the degradation. 


\section{Elongation results}

Elongation measurements on unstrained tensile specimens were made at all four hightemperature conditions; the results for the MCC and M compounds are listed in Tables A14 and A-15, respectively. Since only limited results were obtained under the combined radiation plus temperature conditions, it was difficult to estimate shift factors for the temperature differences. Nonetheless, multiplying the times for the $200^{\circ} \mathrm{C}$ results by 0.53 , a number consistent with the $10 \mathrm{kcal} / \mathrm{mol}$ used previously for the combined environments, led to reasonable superposition of the normalized results, as shown in Figs. 24 and 25 . Since more data existed for the thermal-only experiments, empirical shift factors could be estimated. For the MCC material, a shift factor of 0.19 led to optimal superposition, as shown in Fig. 26. This shift factor corresponded to an activation energy of $\sim 26 \mathrm{kcal} / \mathrm{mol}$, compared to $\sim 29 \mathrm{kcal} / \mathrm{mol}$ for the thermal-only CS data. Given the very limited range of temperatures probed for the elongation data, these results should be considered consistent within experimental error. For the $\mathrm{M}$ material, a shift factor of 0.30 led to optimal superposition, as shown in Fig. 27. This shift factor corresponded to an activation energy of $\sim 19 \mathrm{kcal} / \mathrm{mol}$, compared to $\sim 17 \mathrm{kcal} / \mathrm{mol}$ for the thermal-only CS data. Again, given the very limited range of temperatures probed for the elongation data, these results should be considered consistent within experimental error. The above implies that for each of the two separate environments (radiation plus thermal and thermal-only), the chemistry responsible for drops in elongation may be similar to the chemistry governing the CSR and CS results. This does not necessarily mean, however, that the same chemistry holds for both the combined radiation plus ternperature environment and the thermal-only environment.

\section{Importance of diffusion-limited oxidation (DLO)-Theoretical estimate}

A question that needs to be addressed is the importance of diffusion-limited oxidation (DLO) to the results. DLO can occur whenever the rate of dissolved oxygen consumption in the interior of an aging sample is greater than the rate at which the oxygen can be replenished by diffusion from the surrounding air atmosphere [9, 11-14]. This effect will lead to reduced oxidation in the interior region of the material and the potential of anomalous behavior, which will be geometry dependent. The importance of DLO can be estimated from knowledge of the material geometry plus estimates of the oxygen permeability coefficient $\left(P_{\mathrm{Ox}}\right)$ and the oxygen consumption rate $(\varphi)$. In particular, the approximate distance $\left(l_{\mathrm{Ox}}\right)$ that oxidation reaches into a sample from its air-exposed outer surface is given by [12]

$$
l_{\mathrm{Ox}} \approx\left[\frac{p P_{\mathrm{Ox}}}{\varphi}\right]^{0.5}
$$

where $p$ is the oxygen partial pressure surrounding the sample. For unfilled polydimethylsiloxane at $30^{\circ} \mathrm{C}, P_{\text {Ox }}$ equals $\sim 6 \times 10^{-8} \mathrm{ccSTP} / \mathrm{cm} / \mathrm{s} / \mathrm{cmHg}$ [15]. Since the 
activation energy for $P_{\mathrm{Ox}}$ of silicone materials is close to 0 , we will make a rough estimate that $P_{\mathrm{Ox}} \sim 6 \times 10^{-8}$ at $230^{\circ} \mathrm{C}$. In room temperature radiation environments, values of $\varphi$ typically range from 1 to $10 \times 10^{-10} \mathrm{~mol} / \mathrm{g} / \mathrm{Gy}$; we will guess that the lower part of the range is appropriate for silicone materials and that $\varphi$ will increase by a factor of 20 under combined radiation plus $230^{\circ} \mathrm{C}$ (i.e., the decay of $F / F_{0}$ is $\sim 20$ times faster as seen in Figs. 5 and 6); in other words, we estimate $\varphi \sim 2 \times 10^{-9} \mathrm{~mol} / \mathrm{g} / \mathrm{Gy}$ at $230^{\circ} \mathrm{C}$ plus $6 \mathrm{kGy} / \mathrm{h}$.

Substituting these values in the above equation leads to an $l_{\mathrm{Ox}}$ estimate of approximately $1 \mathrm{~mm}$ under $230^{\circ} \mathrm{C}$ plus $6 \mathrm{kGy} / \mathrm{h}$ aging conditions. Since the tensile specimens are $\sim 2$ $\mathrm{mm}$ thick, this result implies that DLO effects may be unimportant for the tensile results. On the other hand, DLO effects would be expected to be quite important for the 29-mm diameter disk samples used for the CSR and CS tests. Although numerous assumptions are made to arrive at the above estimate, the square root dependence of the equation for $l_{\mathrm{Ox}}$ shows that even an order of magnitude error in the estimate of $P_{\mathrm{OX}} / \varphi$ will not alter the conclusion that the CSR samples must have important DLO effects.

\section{Importance of DLO- Experimental measurements using modulus profiling}

To experimentally determine the importance of DLO effects, a limited number of modulus profiles were taken on representative samples. Figure 28 shows several modulus profiles taken across the cross-section of MCC tensile specimens. The unaged material had fairly uniform modulus values of $\sim 3 \mathrm{MPa}$. After aging at $230^{\circ} \mathrm{C}+5.94$ $\mathrm{kGy} / \mathrm{h}$ for $6 \mathrm{~h}$ and $12 \mathrm{~h}$, the modulus values increased uniformly to $\sim 5$ and $9 \mathrm{MPa}$, respectively. Because of the uniform increases in modulus (caused by oxidation), it is clear that DLO is unimportant for the tensile specimens aged under these conditions, which is consistent with the theoretical predictions of the previous section. For the tensile specimen that was aged for $432 \mathrm{~h}$ at $230^{\circ} \mathrm{C}$ without radiation, little modulus change was observed. Since the 6-h and 12-h combined environment exposures correspond to $\sim 74 \%$ and $\sim 90 \%$ CS (Fig. 10), the results show that the material modulus increases rapidly before the CS reaches large values; this indicates that substantial net crosslinking occurs under combined environment exposures. This is in stark contrast to the $432 \mathrm{~h}$ result for $230^{\circ} \mathrm{C}$ only (little change in modulus) even though CS values reach $95 \%$ after only $90 \mathrm{~h}$ in this environment (Fig. 13). These results show that the chemistry underlying the two different exposure environments must be quite different.

Figure 29 displays several modulus profiles taken across the cross-section of CSR specimens of the $\mathrm{M}$ material. The results start at 0 , which corresponds to the outside of the curved surface of the cylindrically shaped sample, and proceed in part way toward the center along the $29-\mathrm{mm}$ sample diameter. The modulus of the unaged disk is $\sim 2 \mathrm{MPa}$. For a tensile specimen exposed to the combined environment of $230^{\circ} \mathrm{C}+5.91 \mathrm{kGy} / \mathrm{h}$ for $12 \mathrm{~h}$, the modulus increases to $\sim 7 \mathrm{MPa}$ due again to uniform oxidation. For a CSR sample exposed to these identical conditions, the profile indicates that DLO is important. Oxidation at the sample surface is similar to that for the tensile specimen, but DLO effects cause the modulus to drop over the first $1 \mathrm{~mm}$ to an approximately constant value 
of $4 \mathrm{MPa}$ over the remainder of the sample. This $\sim 1 \mathrm{~mm}$ diffusion distance is consistent with the results predicted in the theoretical section above. Since the modulus increases uniformly to $\sim 4 \mathrm{MPa}$ in the anaerobic interior region, it is clear that the radiation causes crosslinking even in the absence of oxygen. Also shown in the figure is a profile for a disk sample aged at $230^{\circ} \mathrm{C}$ for $55 \mathrm{~h}$; little change in modulus is observed for this sample. Since both $12 \mathrm{~h}$ at $230^{\circ} \mathrm{C}+5.91 \mathrm{kGy} / \mathrm{h}$ and $55 \mathrm{~h}$ at $230^{\circ} \mathrm{C}$ correspond to similar CS values of $\sim 95 \%$ (Figs. 10 and 17 ), these results again show that very different chemistry can underlie equivalent $\mathrm{CS}$ changes.

To see whether DLO effects had any influence on the CS measurements, we examined the CS buttons after the completion of aging to see if their recovery thickness was less near the oxidized cylindrical surfaces of the sample. Since no drop-off in recovery thickness could be observed for any of the experimental conditions, it was concluded that the amount of CS was not significantly influenced by whether one was measuring in an oxidized or nonoxidized portion of the sample. In addition, since the dimensions of the actual door seal are similar to the CS sample and our accelerated simulations were done in time frames similar to those predicted for an actual accident, DLO effects seen in our simulations should be similar in magnitude to those that would be observed in a severe accident.

\section{Density results}

Density results also show that very different chemistry occurs under combined radiation plus thermal environments then under thermal-only environments. Figure 30 shows density results for 2-mm-thick MCC tensile specimens exposed to combined environment conditions of $230^{\circ} \mathrm{C}+5.94 \mathrm{kGy} / \mathrm{h}$ and $200^{\circ} \mathrm{C}+5.88 \mathrm{kGy} / \mathrm{h}$ and to thermal-only conditions of $230^{\circ} \mathrm{C}$. Substantial density increases are observed for both combined environment exposures, caused probably by a combination of crosslinking, the incorporation of oxidation products, and possibly shrinkage. These results contrast with the tensile sample results in a $230^{\circ} \mathrm{C}$ environment, where no measurable change in density could be detected for the first $264 \mathrm{~h}$. Again, this points out the differences in the chemistry that is occurring in the two types of environments.

For the CSR disk-shaped samples in combined environments, where DLO effects were identified from the modulus profiling results, density values taken on samples cut from the outer $1 \mathrm{~mm}$ oxidized region increased substantially from $1.1619 \mathrm{~g} / \mathrm{cc}$ for the unaged material to $1.194 \mathrm{~g} / \mathrm{cc}$ and $1.192 \mathrm{~g} / \mathrm{cc}$ for the $35 \mathrm{~h}$ at $5.94 \mathrm{kGy} / \mathrm{h}$ plus $230^{\circ} \mathrm{C}$ sample and the $46 \mathrm{~h}$ at $5.88 \mathrm{kGy} / \mathrm{h}$ plus $200^{\circ} \mathrm{C}$ sample, respectively. The densities of samples taken from the interior (anaerobically aged) regions of these same disks were $1.1586 \mathrm{~g} / \mathrm{cc}$ and $1.1617 \mathrm{~g} / \mathrm{cc}$, respectively. These latter results represent minor increases relative to the unaged interior value of $1.156 \mathrm{~g} / \mathrm{cc}$. Thus the density results for the disk samples show the importance of DLO and imply that crosslinking under anaerobic conditions leads to minor density increases. 


\section{Viton results}

In order to screen for materials that could be substituted for silicone in the door seal environment, CSR and CS measurements were taken on a Viton material at $230^{\circ} \mathrm{C}$ plus $5.55 \mathrm{kGy} / \mathrm{h}$. The force and height data obtained are summarized in Table A-11; these lead to the CSR and CS results plotted in Fig. 31. Comparing these results with those obtained under similar conditions for the MCC and M silicone materials (Figs. 5, 6, and 10 ) indicates that this Viton material has CSR and CS responses superior to the $M$ material and similar to the MCC material.

\section{CONCLUSIONS}

Given the presence of a complex aging environment followed by an even more complex accident scenario, the latter encompassing steam and time-dependent temperatures and dose rates, it would be impossible to exactly simulate all of the degradation effects anticipated for the silicone door seals. By making some reasonable simplifying assumptions, we derived constant temperature and dose-rate combined environments that should do a reasonable job of simulating the complex postulated overall aging plus accident environments anticipated for worst-case severe accidents. We then showed how thermal-only simulations could be used to achieve reasonably similar CSR and CS values; the results are summarized in Table 3. Although such simulations should lead to sealing forces similar to those expected during a severe accident, modulus and density results indicated that differences in chemistry should be expected between thermal-only and combined environment simulations. Diffusion-limited oxidation effects are present for the simulated experiments on 29-mm-diameter disk samples, but DLO effects of similar magnitude would be expected under severe accident conditions.

\section{REFERENCES}

1. K. T. Gillen and R. L. Clough, "A Kinetic Model for Predicting Oxidative Degradation Rates in Combined Radiation-Thermal Environments, " J. Polym. Sci., Polym. Chem. Ed. 23, 2683 (1985).

2. K. T. Gillen and R. L. Clough, "Time-Temperature- Dose Rate Superposition: A Methodology for Extrapolating Accelerated Radiation Aging Data to Low Dose Rate Conditions," Polym. Degrad. Stabil. 24, 137 (1989).

3. K. T. Gillen and R. L. Clough, "Accelerated Aging Methods for Predicting LongTerm Mechanical Performance of Polymers," in Irradiation Effects on Polymers, D. W. Clegg and A. A. Collyer, Eds., Elsevier Applied Science, London, 1991., Ch. 4.

4. K. T. Gillen and R. L. Clough, "Predictive Aging Results in Radiation Environments," Rad. Phys. Chem. 41(6), 803 (1993). 
5. K. T. Gillen, R. L. Clough, G. Ganouna-Cohen, J. Chenion and G. Delmas, "The Importance of Oxygen in LOCA Simulation Tests," Nuclear Eng. Design 74, 271 (1982).

6. K. T. Gillen, R. L. Clough and L. H. Jones, "Investigation of Cable Deterioration in the Containment Building of the Savannah River Nuclear Reactor," SAND81-2613 Sandia Labs, Albuquerque, NM, USA (August, 1982).

7. ASTM Standard D395-89, "Standard Test Methods for Rubber PropertyCompression Set."

8. K. T. Gillen, R. L. Clough and C. A. Quintana, "Modulus Profiling of Polymers," Polym. Degrad. Stabil. 17, 31 (1987).

9. K. T. Gillen and R. L. Clough, "Techniques for Monitoring Heterogeneous Oxidation of Polymers," in Handbook of Polymer Science and Technology, Vol. 2, N. P. Cheremisinoff, Ed., Marcel Dekker, New York, 1989, Ch. 6.

10. K. T. Gillen and R. L. Clough. "Polymer Insights Available from Modulus Profiling Data," Polym. Eng. Sci. 29, 29 (1989).

11. R. L. Clough and K. T. Gillen, "Oxygen Diffusion Effects in Thermally Aged Elastomers," Polym. Degrad. Stabil. 38, 47 (1992).

12. K. T. Gillen and R. L. Clough, "Rigorous Experimental Confirmation of a Theoretical Model for Diffusion-Limited Oxidation," Polymer 33, 4358 (1992).

13. J. S. Wise, K. T. Gillen and R. L. Clough, "Quantitative Model for the Time Development of Diffusion-Limited Oxidation Profiles," Polymer 38, 1929 (1997).

14. J. S. Wise, K. T. Gillen and R. L. Clough, "Time-Development of Diffusion-Limited Oxidation Profiles in a Radiation Environment," Radiat. Phys. Chem. (in press).

15. V. T. Stannett, "Barrier Properties and Migration Problems of Polymers," Polym. Eng. Sci. 18, 1129 (1978). 


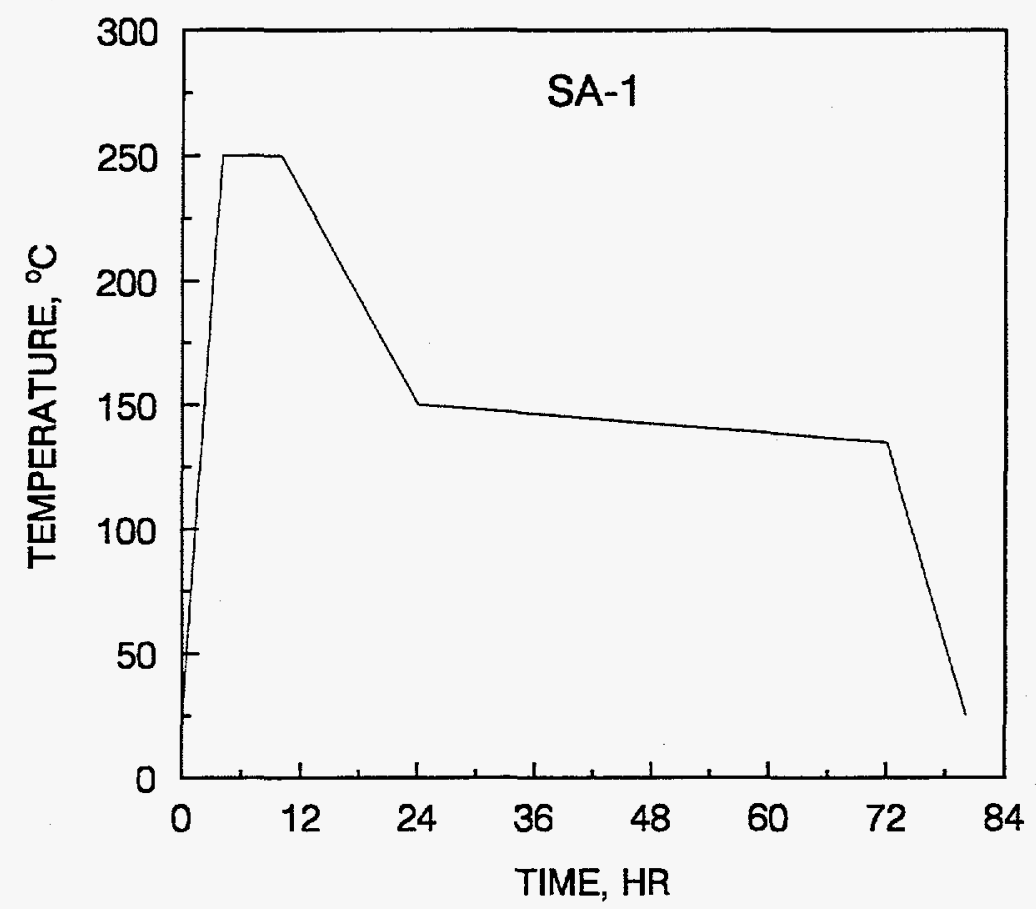

Figure 1. Temperature profile for Italian Severe Accident SA-1.

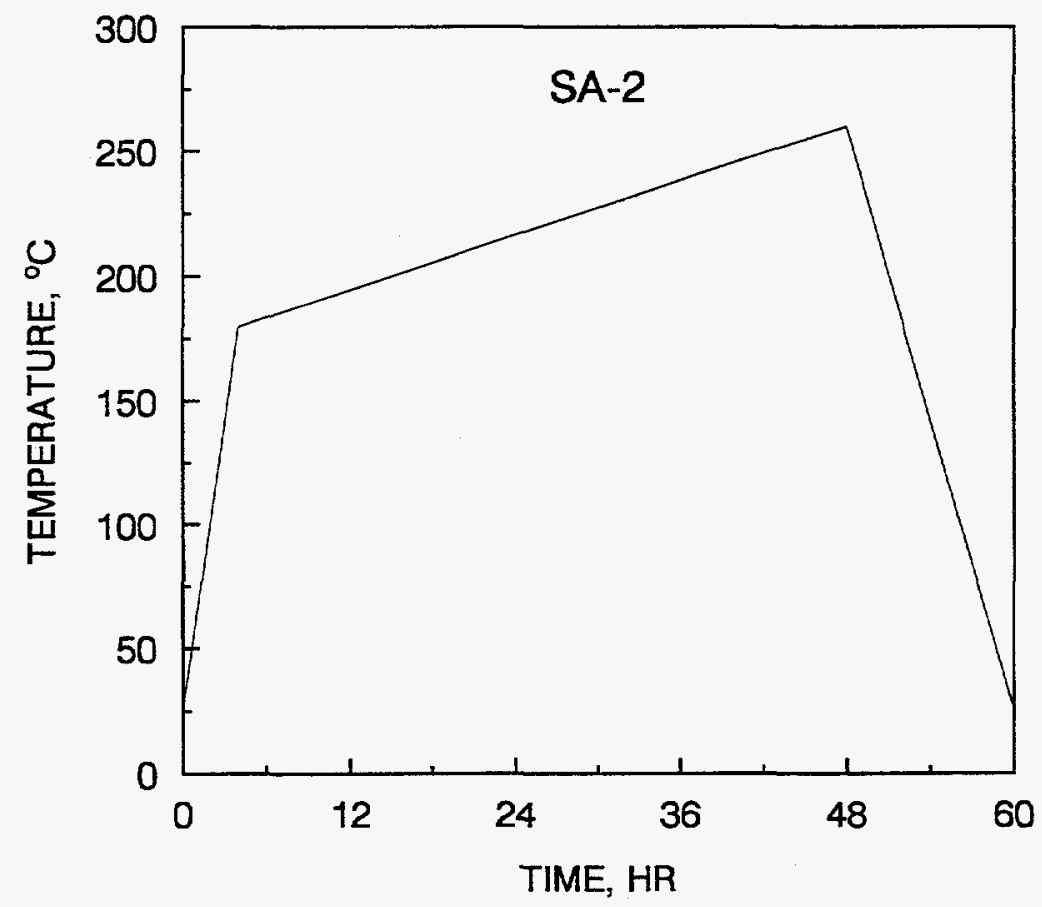

Figure 2. Temperature profile for Italian Severe Accident SA-2. 


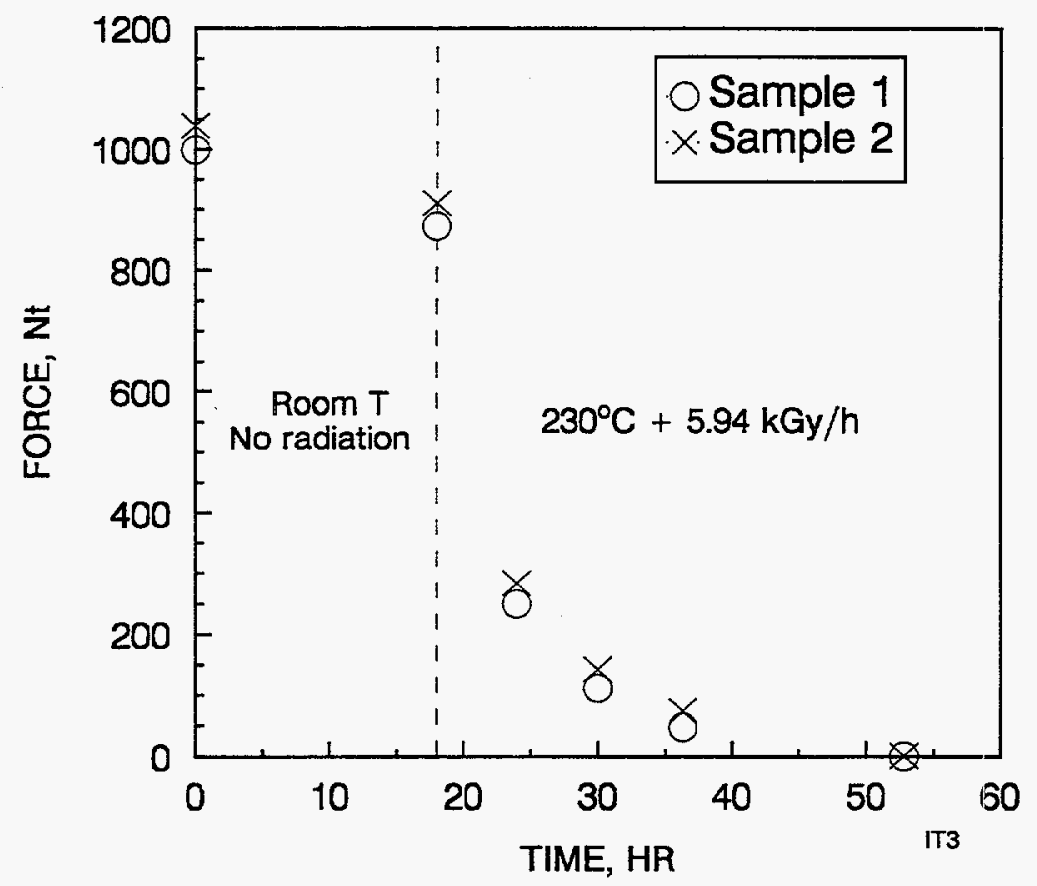

Figure 3. Time-dependent force plots for $\mathrm{MCC}$ samples at $230^{\circ} \mathrm{C}+5.94 \mathrm{kGy} / \mathrm{h}$.

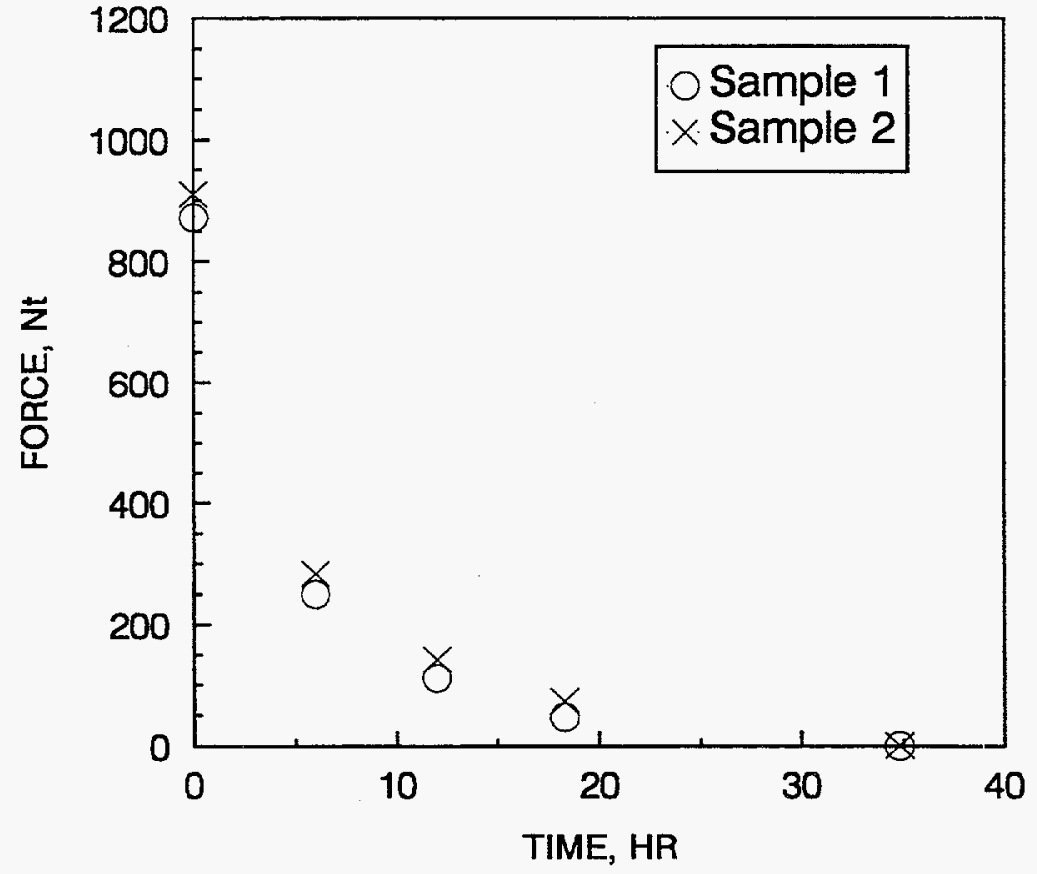

Figure 4. Time-dependent force plots for MCC samples at $230^{\circ} \mathrm{C}+5.94 \mathrm{kGy} / \mathrm{h}$ starting at time when the sample was placed into the aging environment. 


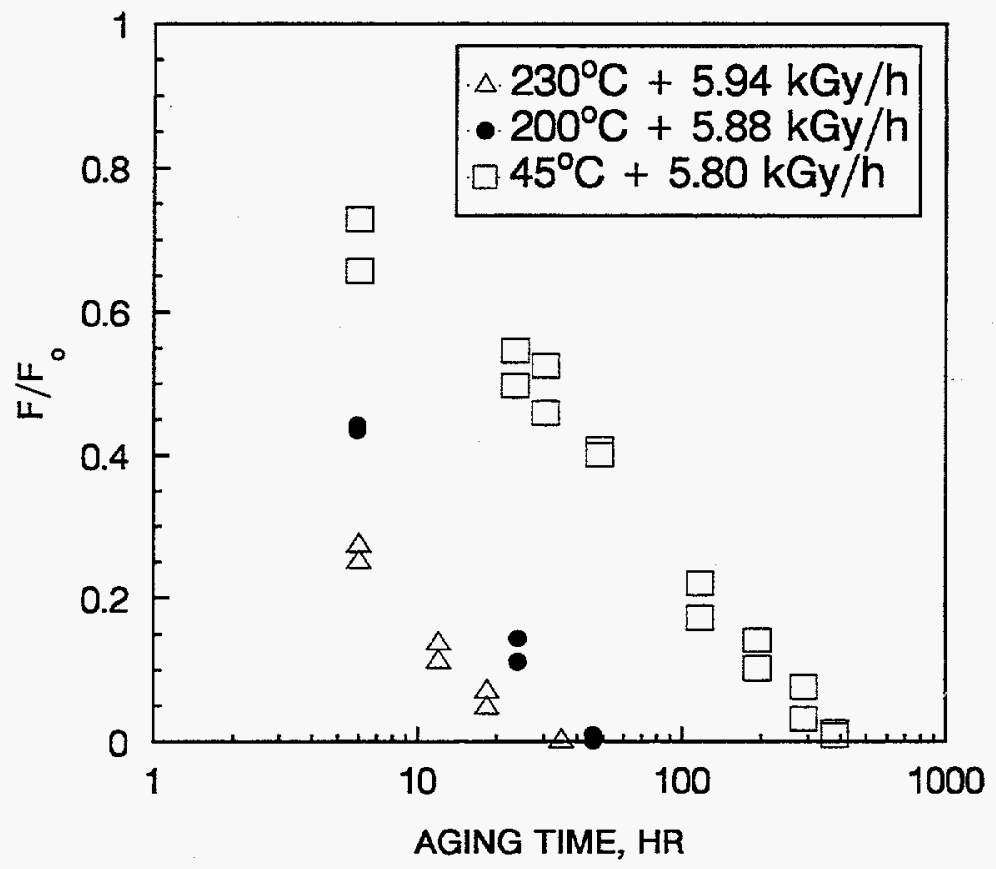

Figure 5. Normalized CSR results for the MCC material under the three indicated combined environment aging conditions.

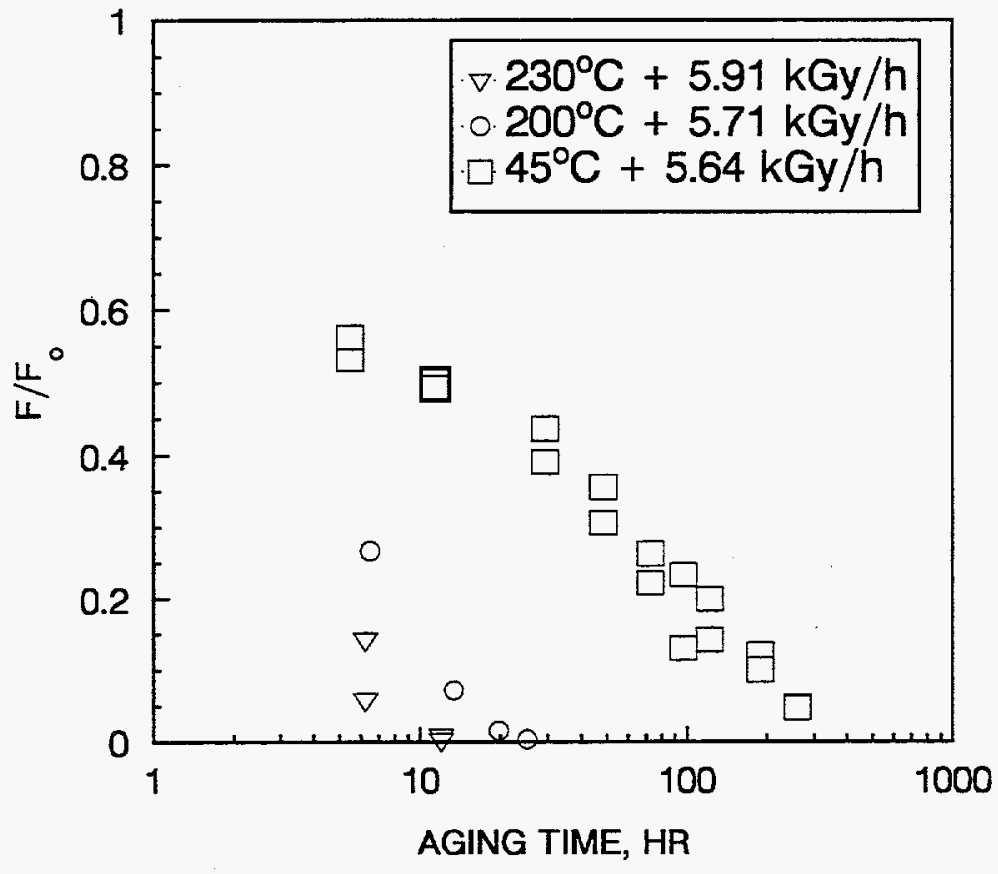

Figure 6. Normalized CSR results for the M material under the three indicated combined environment aging conditions. 


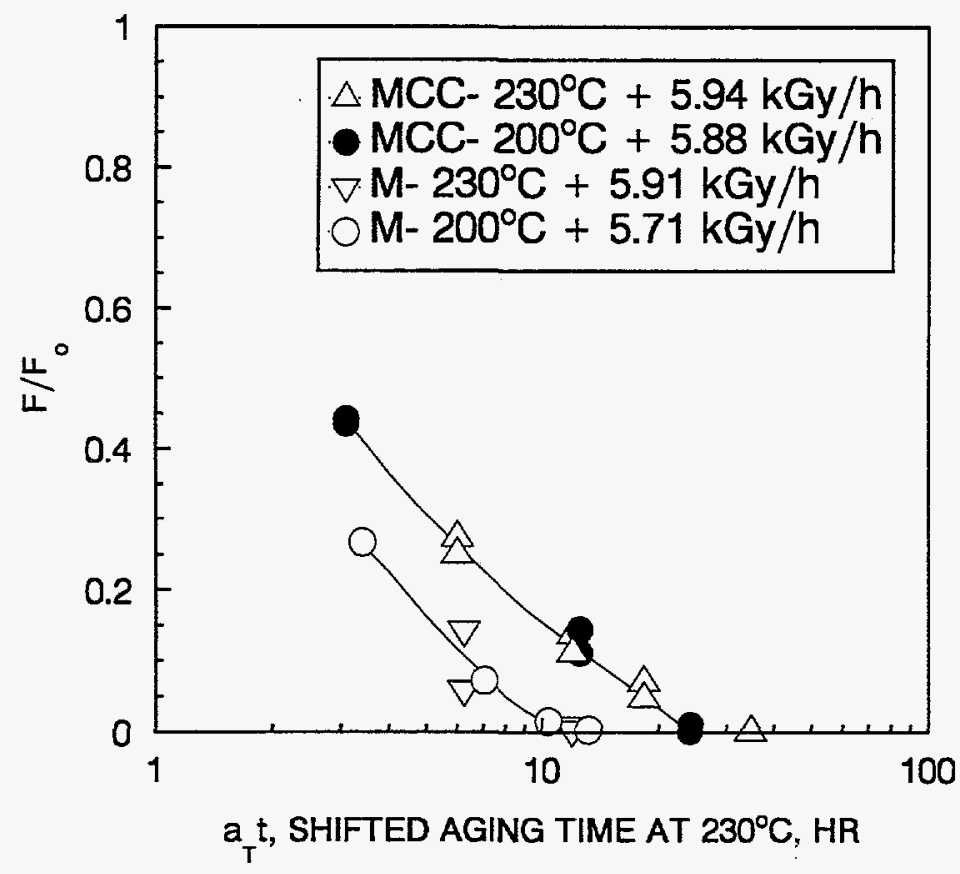

Figure 7. Time-temperature superposition of the high-temperature combined environment results in Figs. 5 and 6 achieved by multiplying the times for the $200^{\circ} \mathrm{C}$ data by 0.53 .

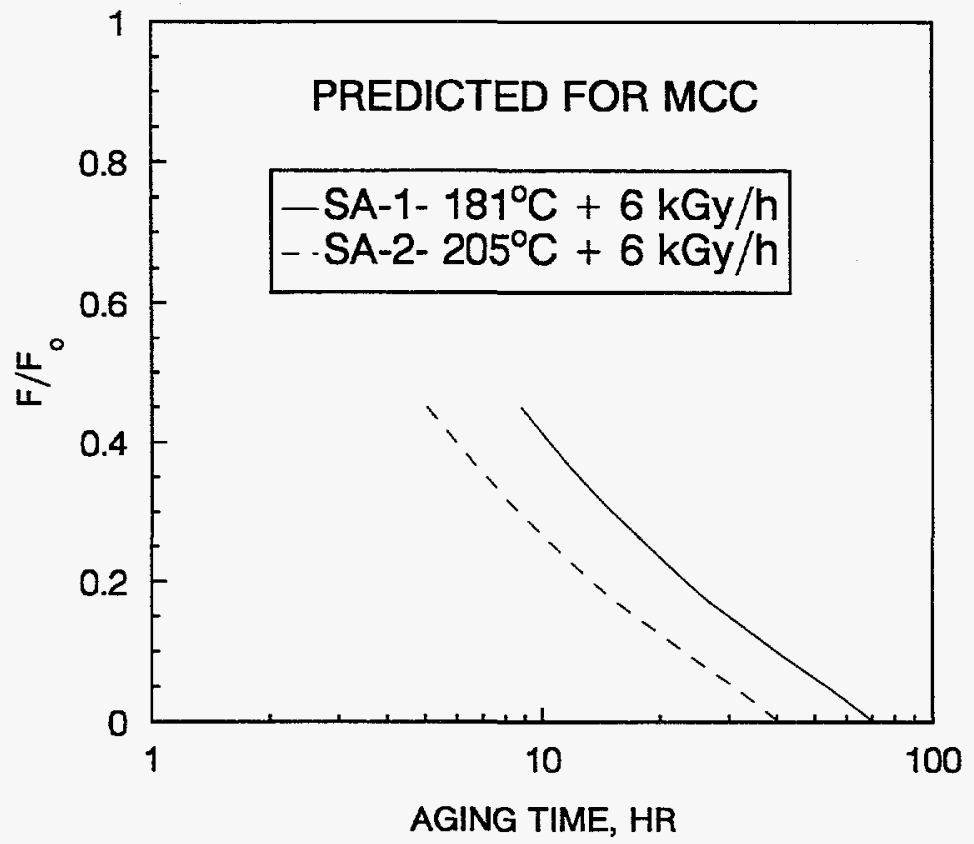

Figure 8. Predicted CSR results obtained for the MCC material under combined environment conditions chosen to simulate SA-1 and SA-2. 


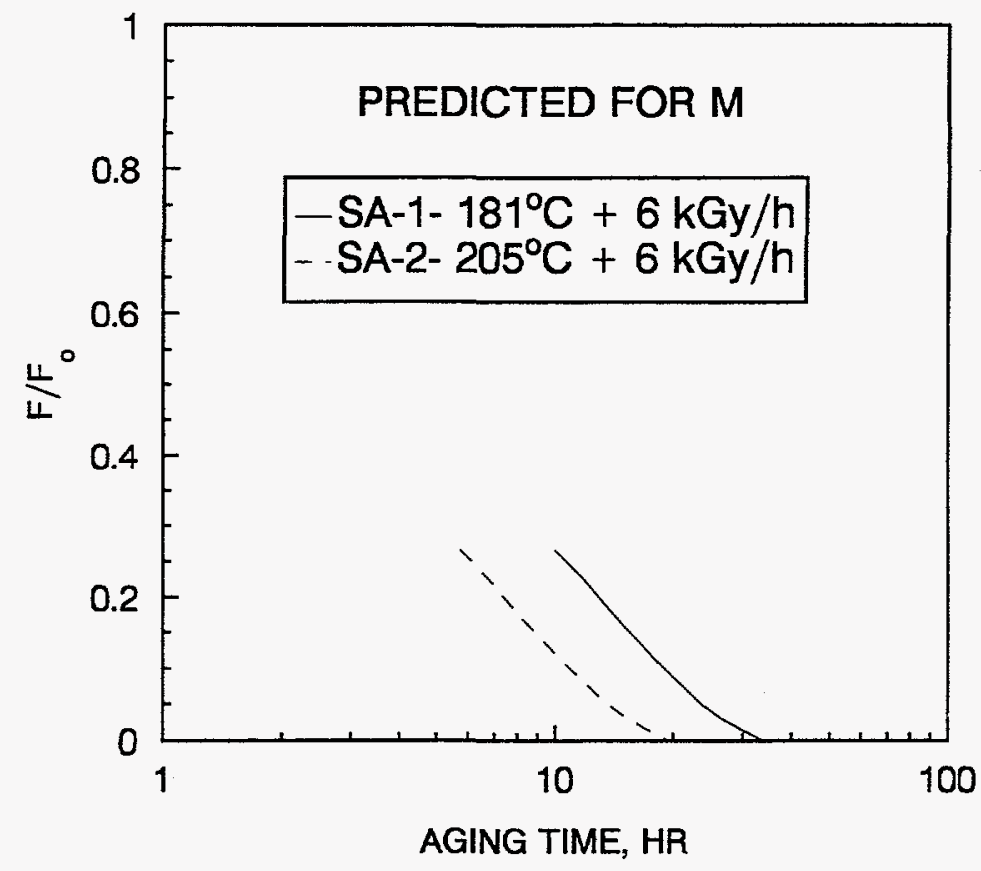

Figure 9. Predicted CSR results obtained for the $M$ material under combined environment conditions chosen to simulate SA-1 and SA-2.

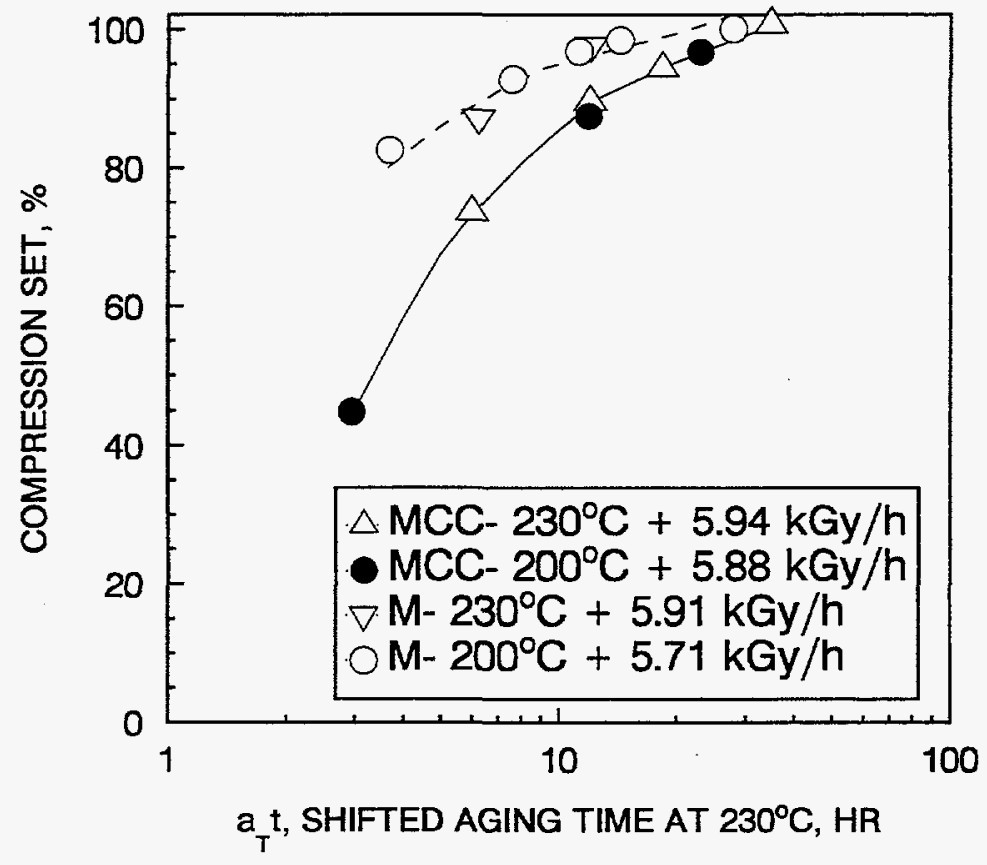

Figure 10. Time-temperature superposition of the high-temperature combined environment $\mathrm{CS}$ results for both the MCC and M materials. 


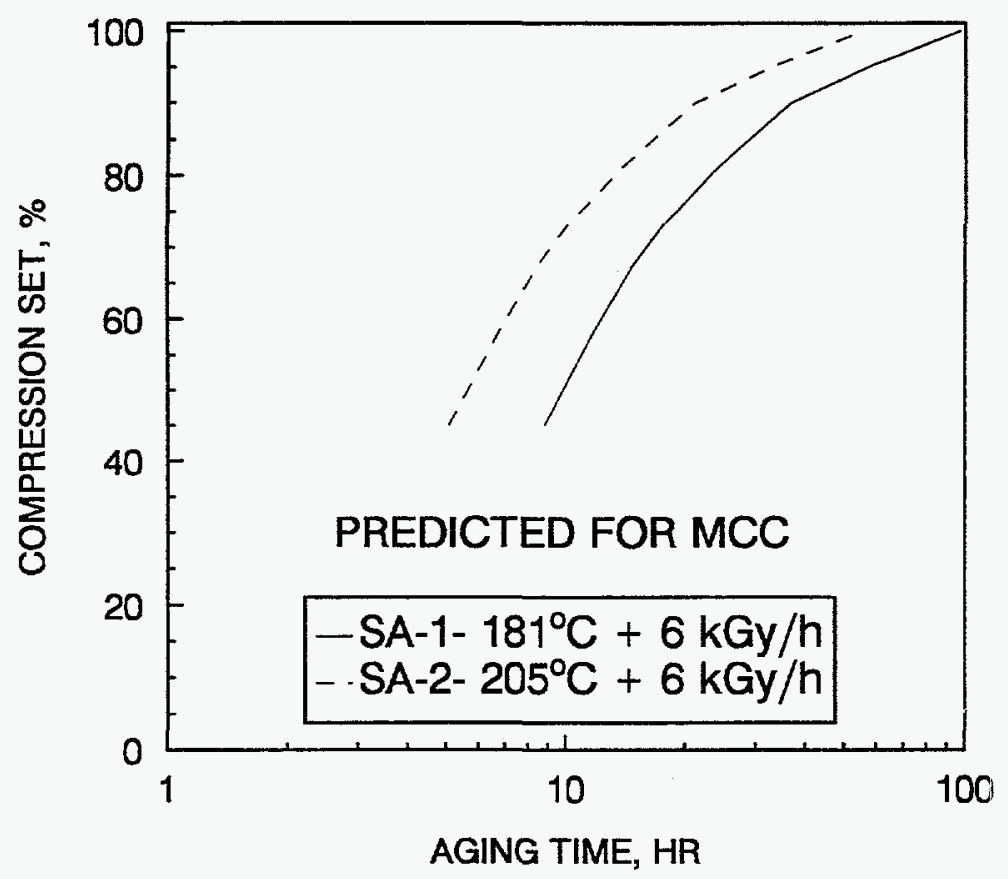

Figure 11. Predicted CS results obtained for the MCC material under combined environment conditions chosen to simulate SA-1 and SA-2.

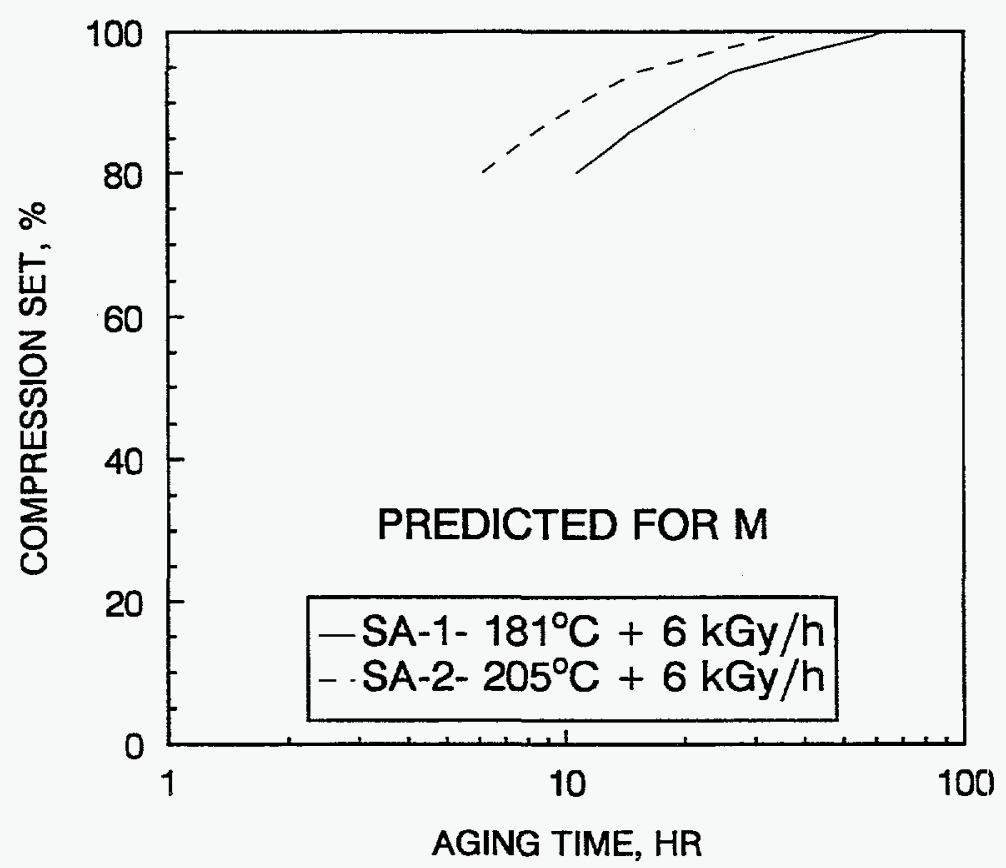

Figure 12. Predicted CS results obtained for the $\mathrm{M}$ material under combined environment conditions chosen to simulate SA-1 and SA-2. 


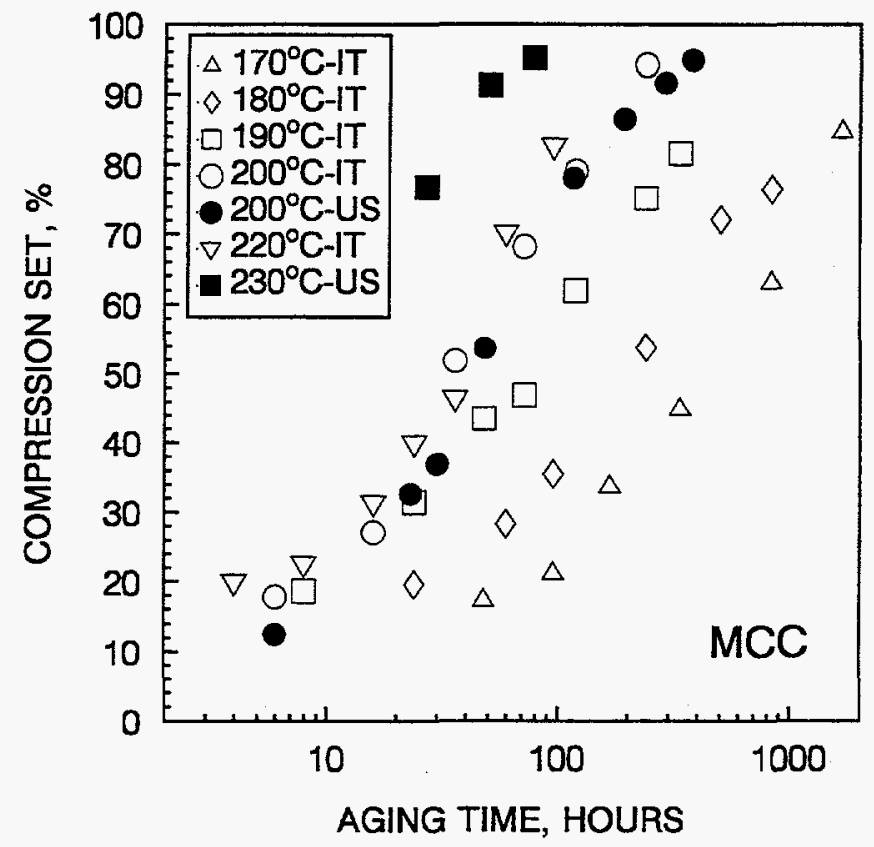

Figure 13. Italian and U. S. CS results for the MCC material in thermal-only environments.

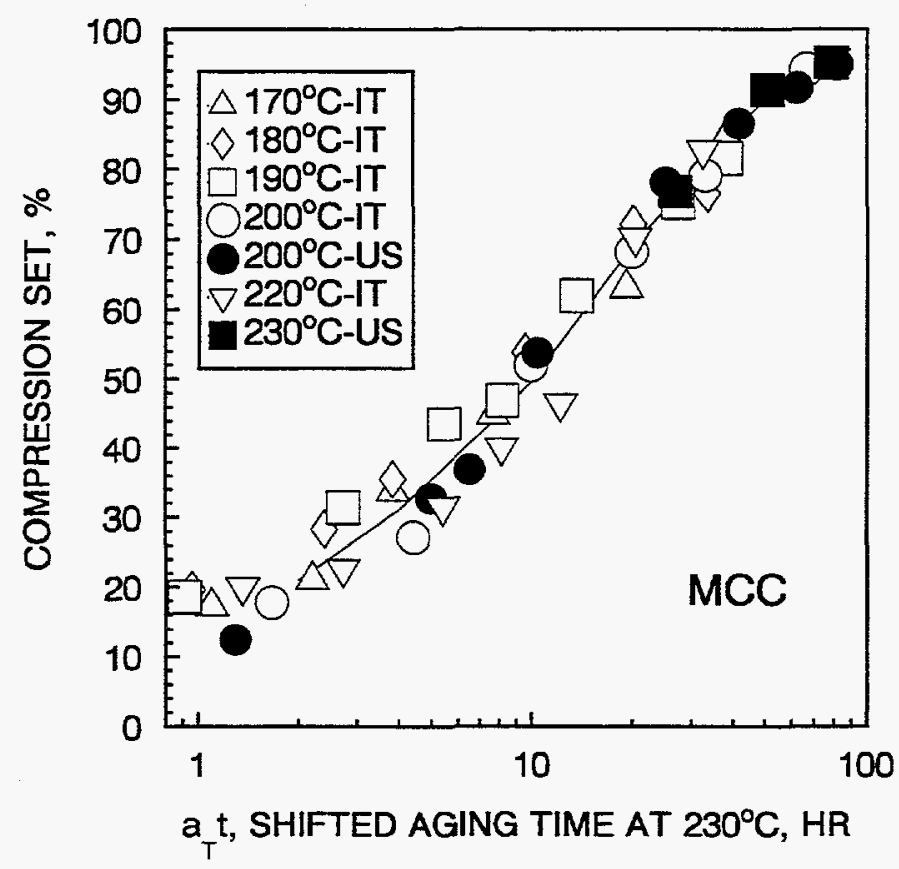

Figure 14. Time-temperature superposition of the thermal-only CS data from Fig. 13. 


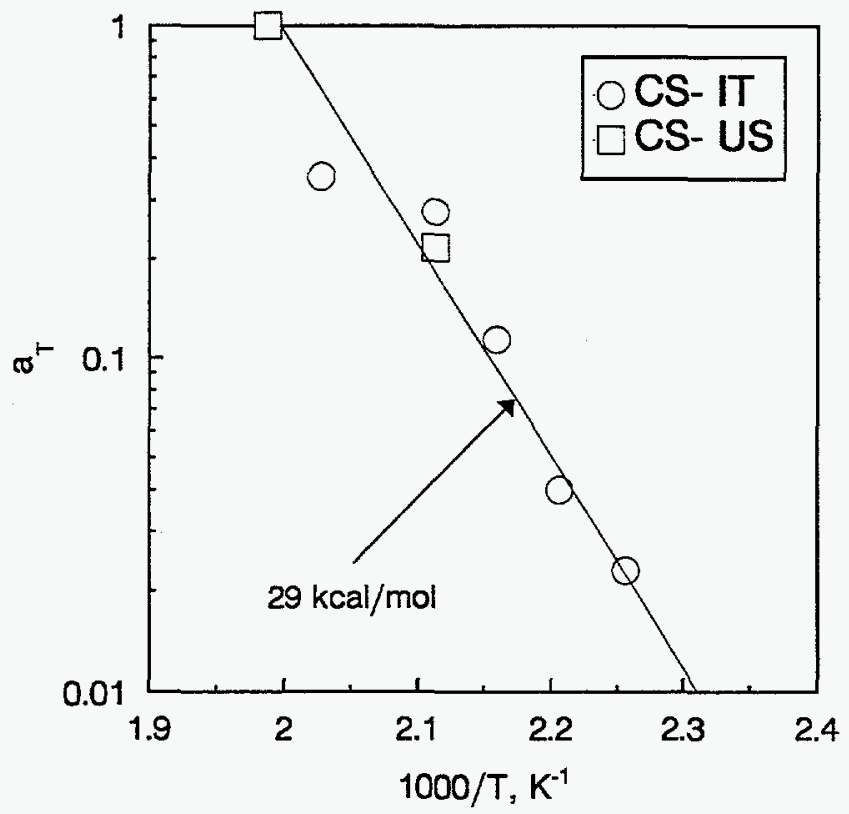

Figure 15. Arrhenius plot of the empirical shift factors used to achieve the timetemperature superposition shown in Fig. 14.

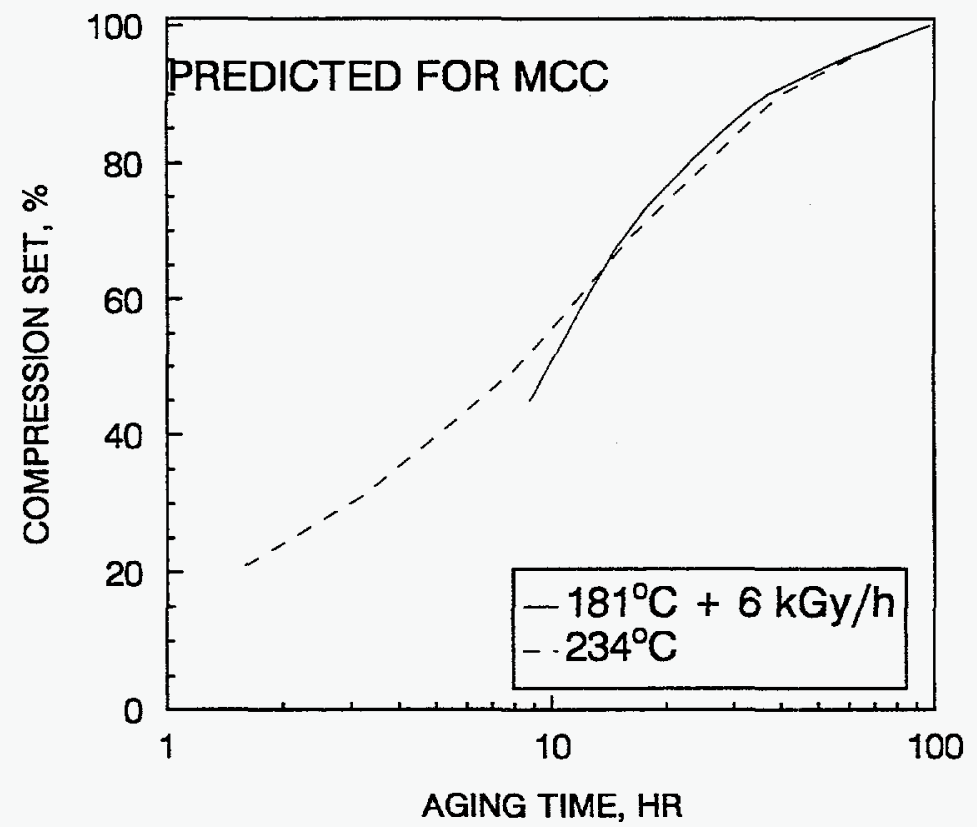

Figure 16. Empirical shift of the $230^{\circ} \mathrm{C}$ superposed curve for the MCC material from Fig. 14 to thermal-only conditions that best match the combined environment conditions found to be equivalent to SA-1 in Fig. 11. 


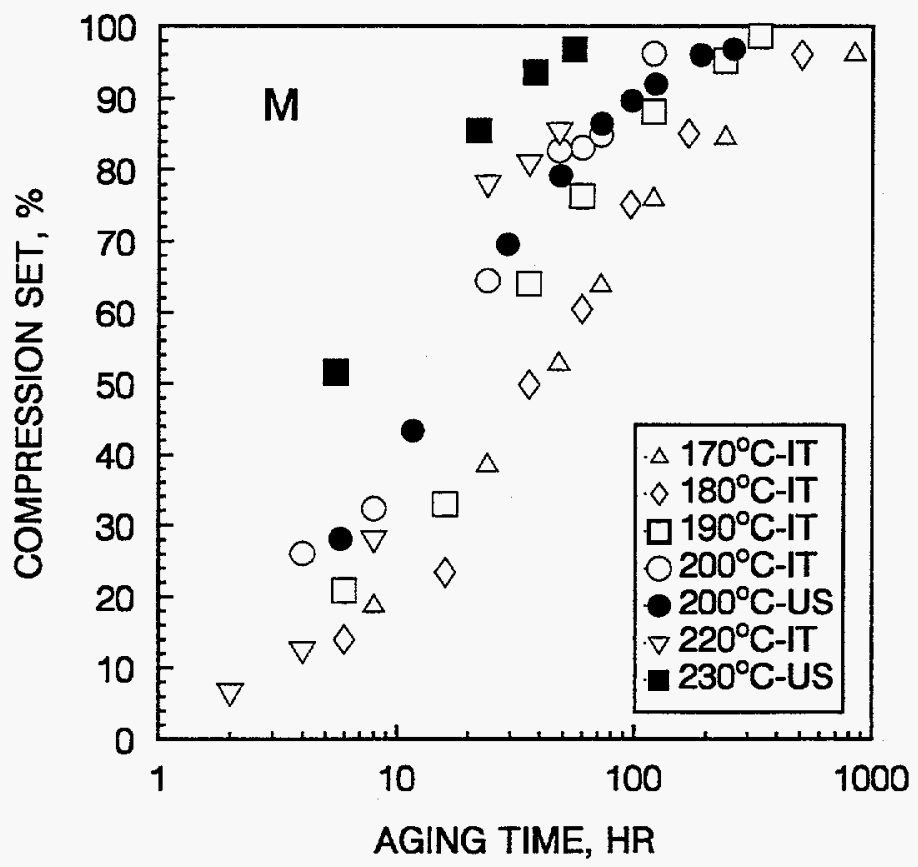

Figure 17. Italian and U. S. CS results for the M material in thermal-only environments.

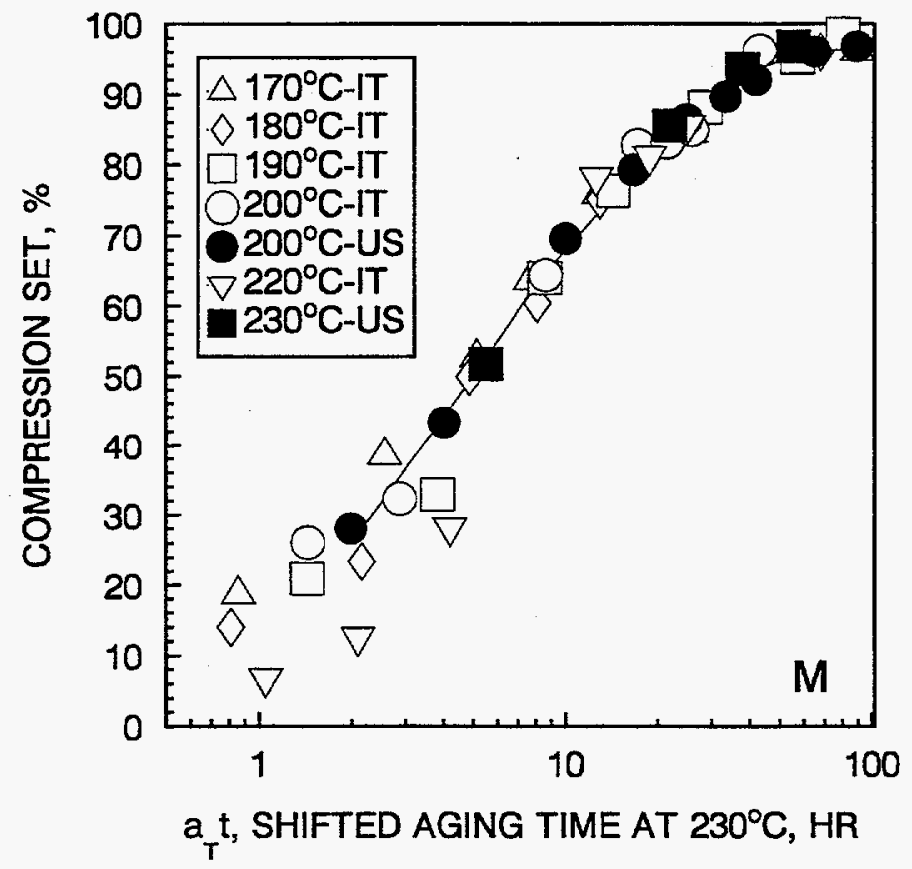

Figure 18. Time-temperature superposition of the thermal-only CS data from Fig. 17. 


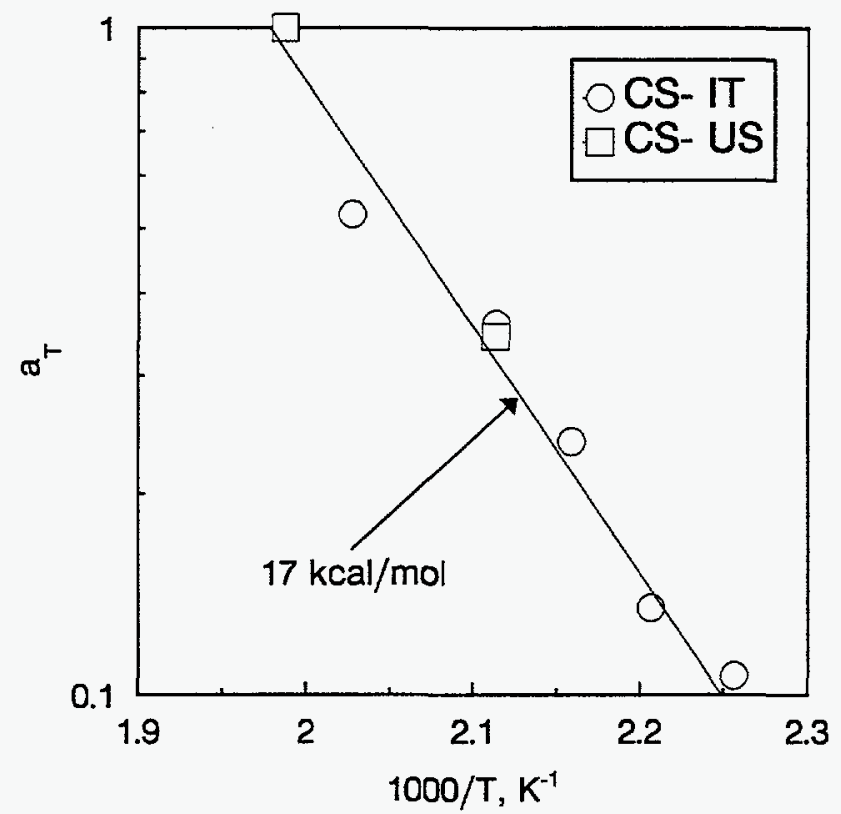

Figure 19. Arrhenius plot of the empirical shift factors used to achieve the timetemperature superposition shown in Fig. 18.

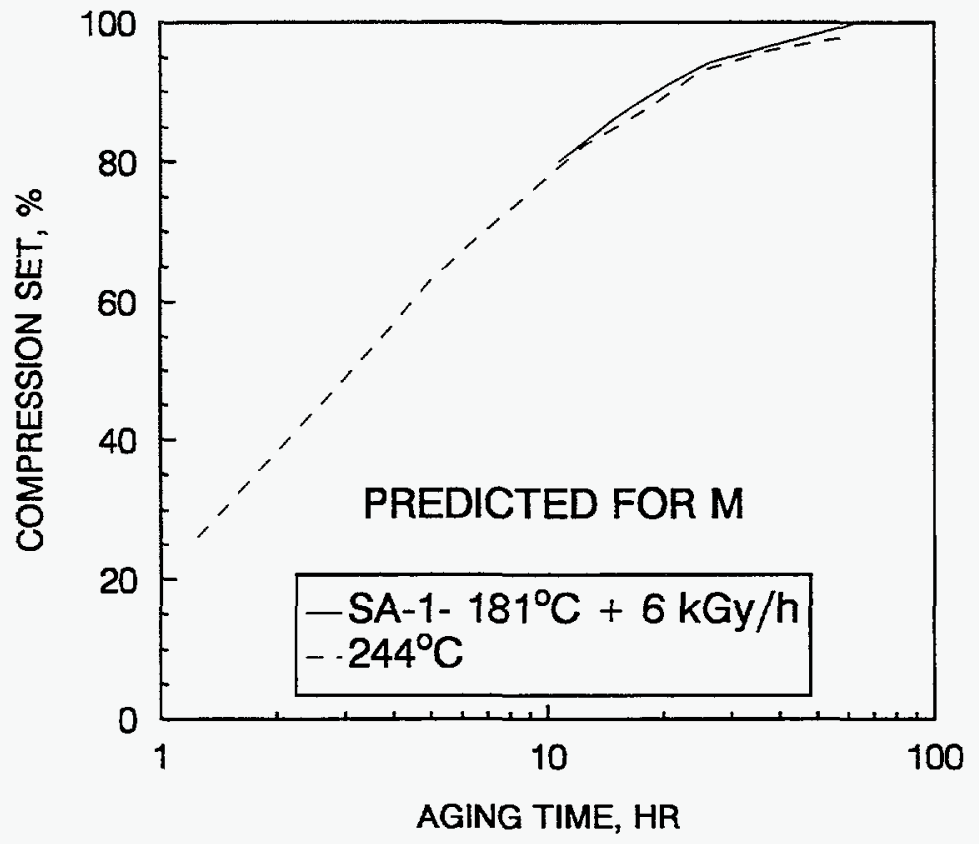

Figure 20. Empirical shift of the $230^{\circ} \mathrm{C}$ superposed curve for the M material from Fig. 18 to thermal-only conditions that best match the combined environment conditions found to be equivalent to SA-1 in Fig. 12. 


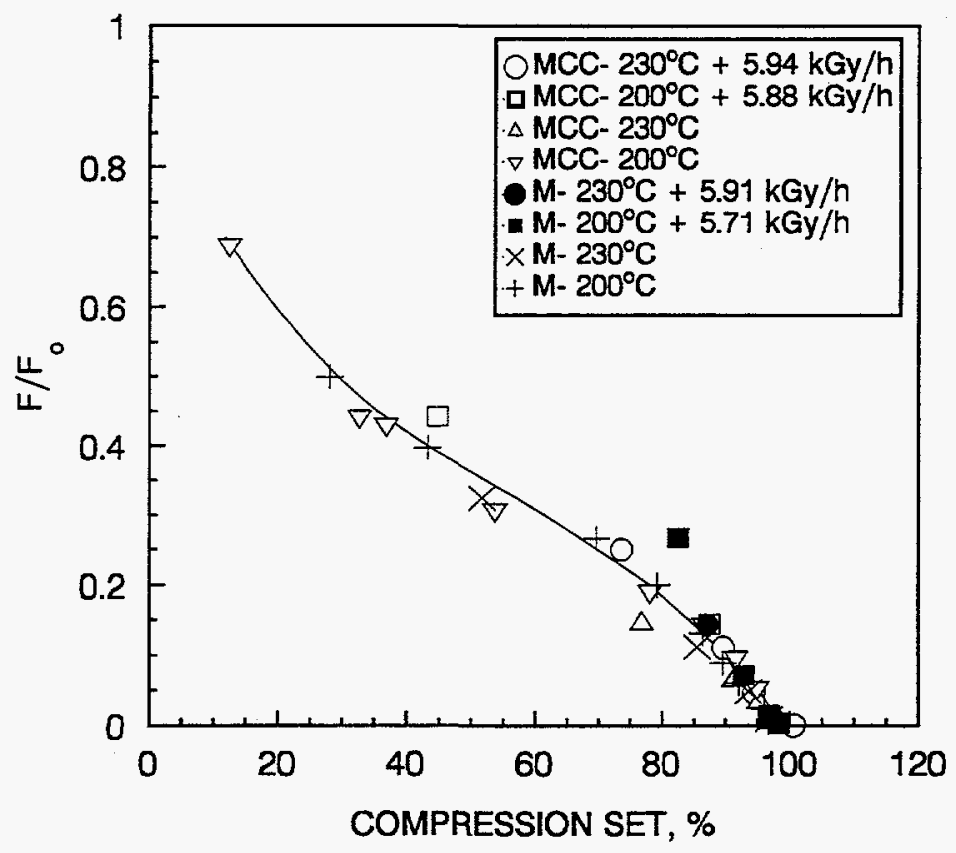

Figure 21. Correlation of CSR and CS results for both MCC and M materials under all high-temperature aging conditions.

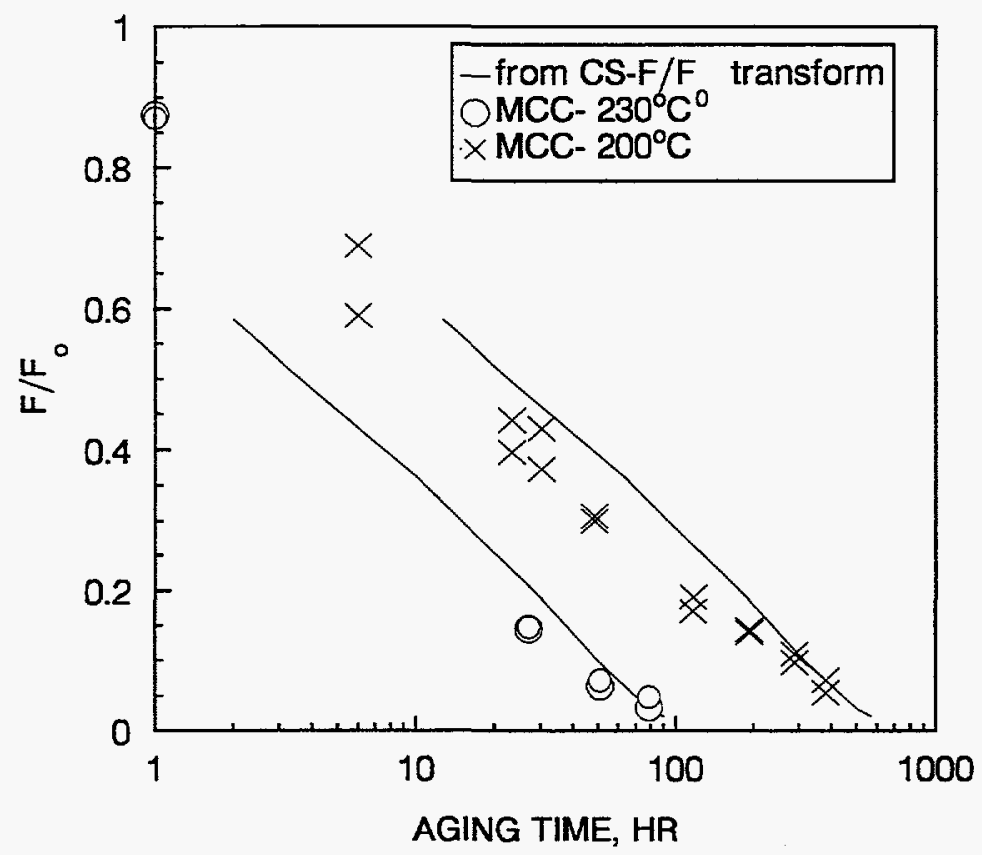

Figure 22. Thermal-only CSR results for the MCC material compared with predicted CSR results obtained by transforming the CS results of Fig. 14 with the transform curve from Fig. 21. 


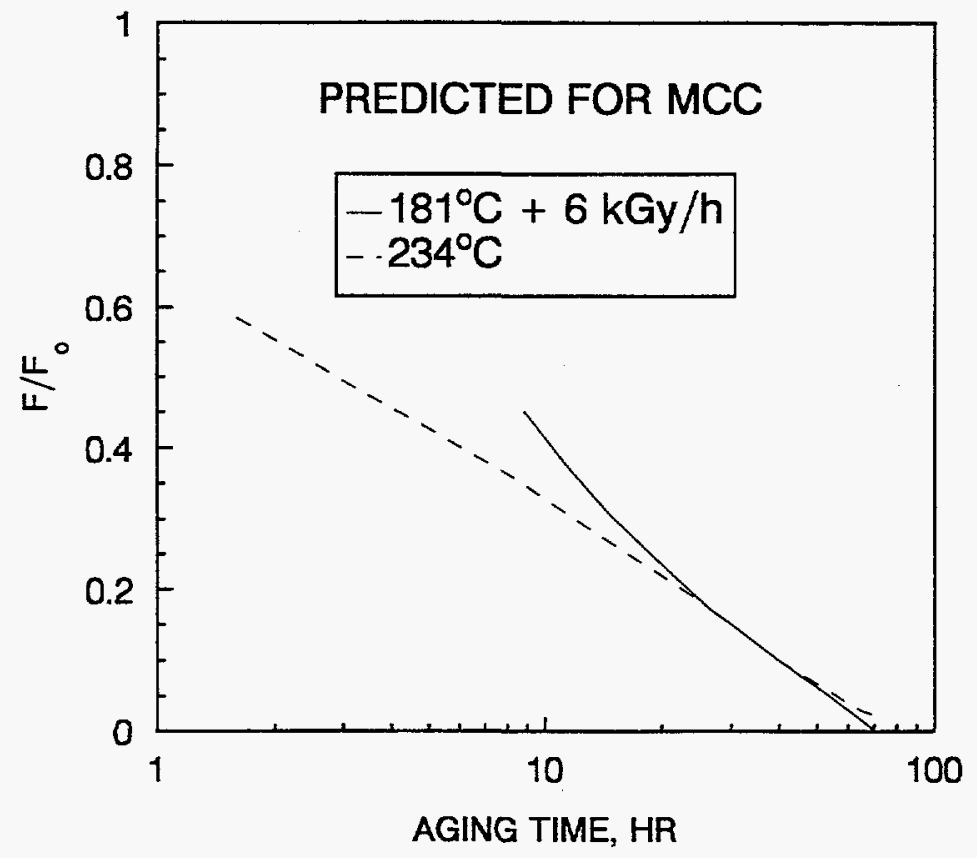

Figure 23. Comparison of the transformed CSR result for $234^{\circ} \mathrm{C}$ with the combined environment result predicted to simulate SA-1.

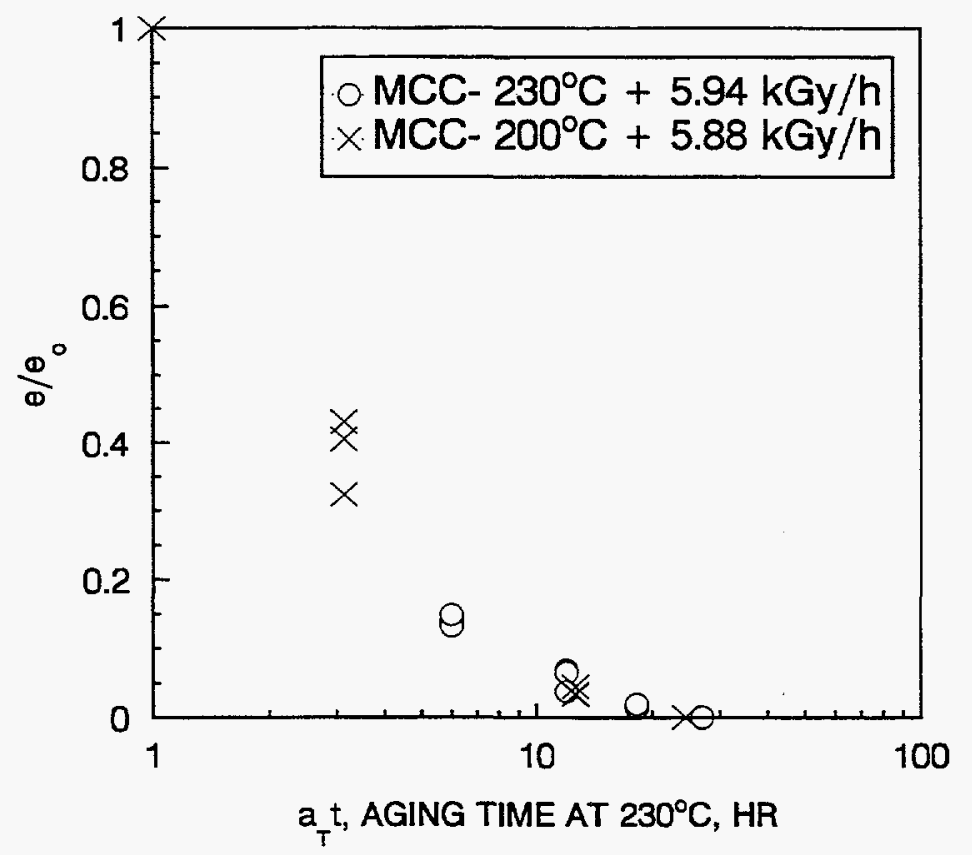

Figure 24. Time-temperature superposition of combined environment normalized tensile elongation data (the elongation $e$ divided by its unaged value, $e_{0}$ ) for the MCC material using the same $10 \mathrm{kcal} / \mathrm{mol}$ activation energy found to apply to CSR and CS results. 


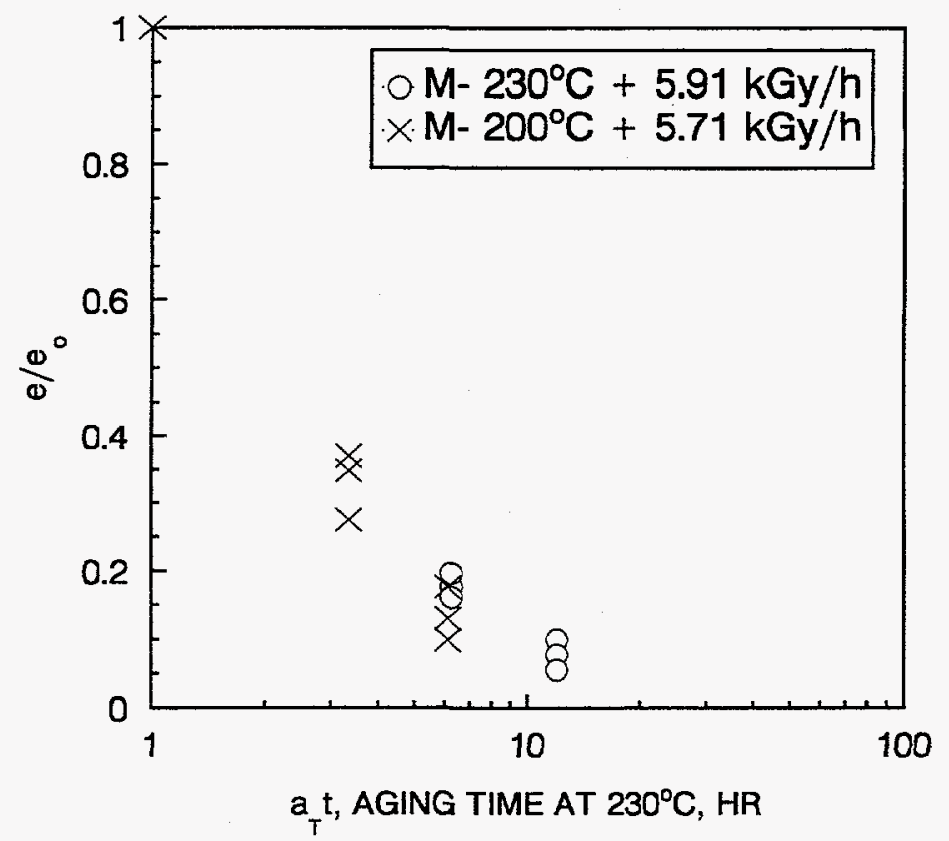

Figure 25. Time-temperature superposition of combined environment normalized tensile elongation data for the $\mathrm{M}$ material using the same $10 \mathrm{kcal} / \mathrm{mol}$ activation energy found to apply to CSR and CS results.

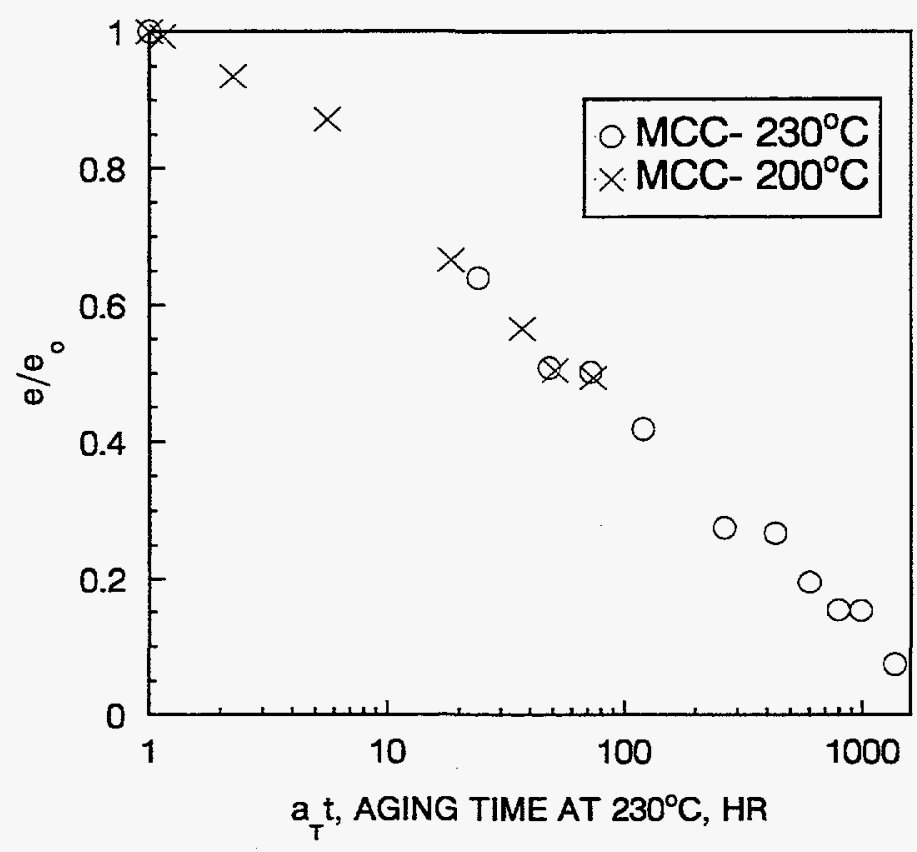

Figure 26. Time-temperature superposition of thermal-only normalized tensile elongation data for the MCC material using a shift factor of 0.19 , which corresponds to an activation energy of $\sim 26 \mathrm{kcal} / \mathrm{mol}$, similar to the $29 \mathrm{kcal} / \mathrm{mol}$ found to apply to CS results. 


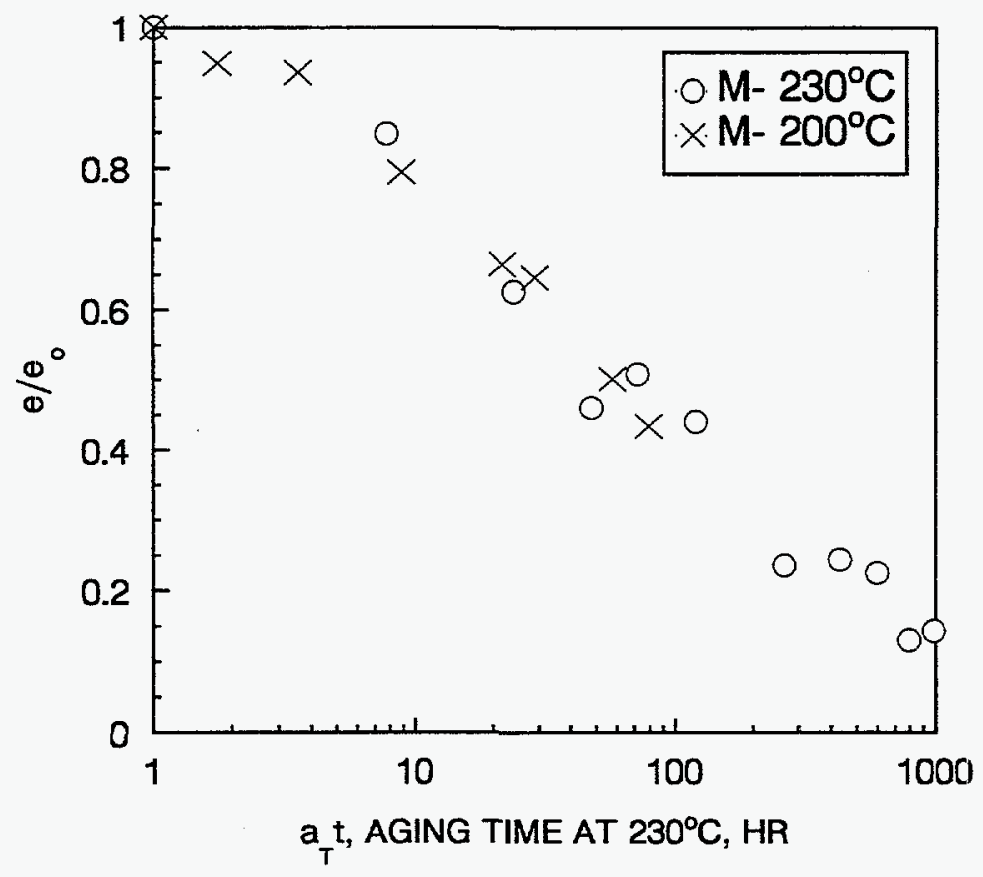

Figure 27. Time-temperature superposition of thermal-only normalized tensile elongation data for the $M$ material using a shift factor of 0.19 , which corresponds to an activation energy of $\sim 19 \mathrm{kcal} / \mathrm{mol}$, similar to the $17 \mathrm{kcal} / \mathrm{mol}$ found to apply to C.S results.

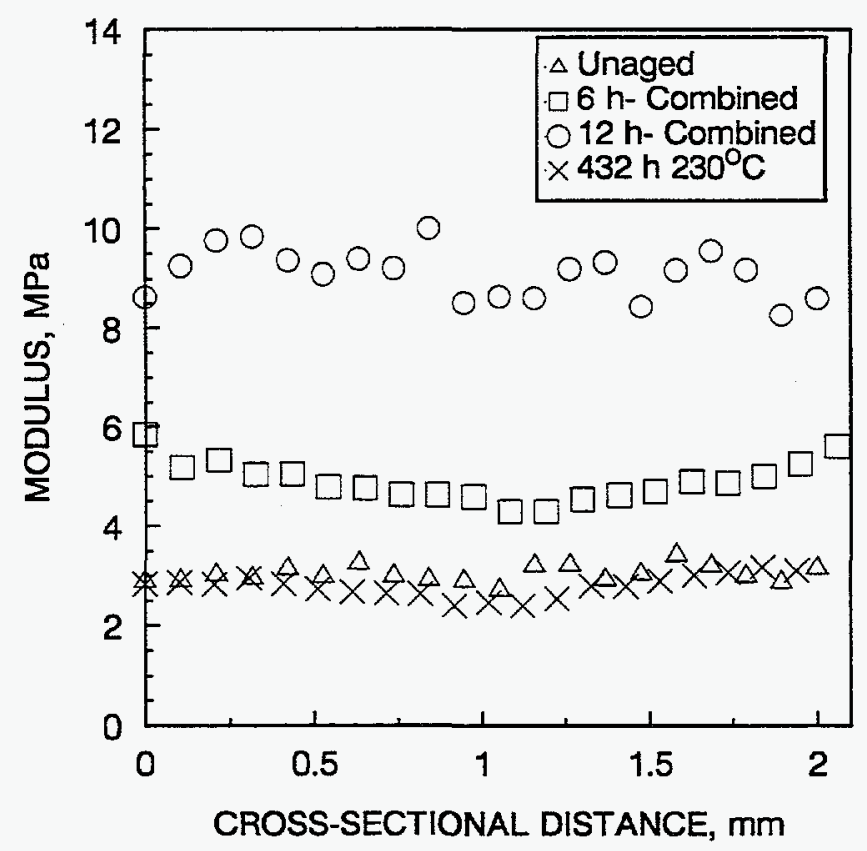

Figure 28. Modulus profile results for $\sim 2$-mm-thick MCC tensile specimens aged under combined $\left(5.94 \mathrm{kGy} / \mathrm{h}\right.$ plus $\left.230^{\circ} \mathrm{C}\right)$ and $230^{\circ} \mathrm{C}$ thermal-only conditions. 


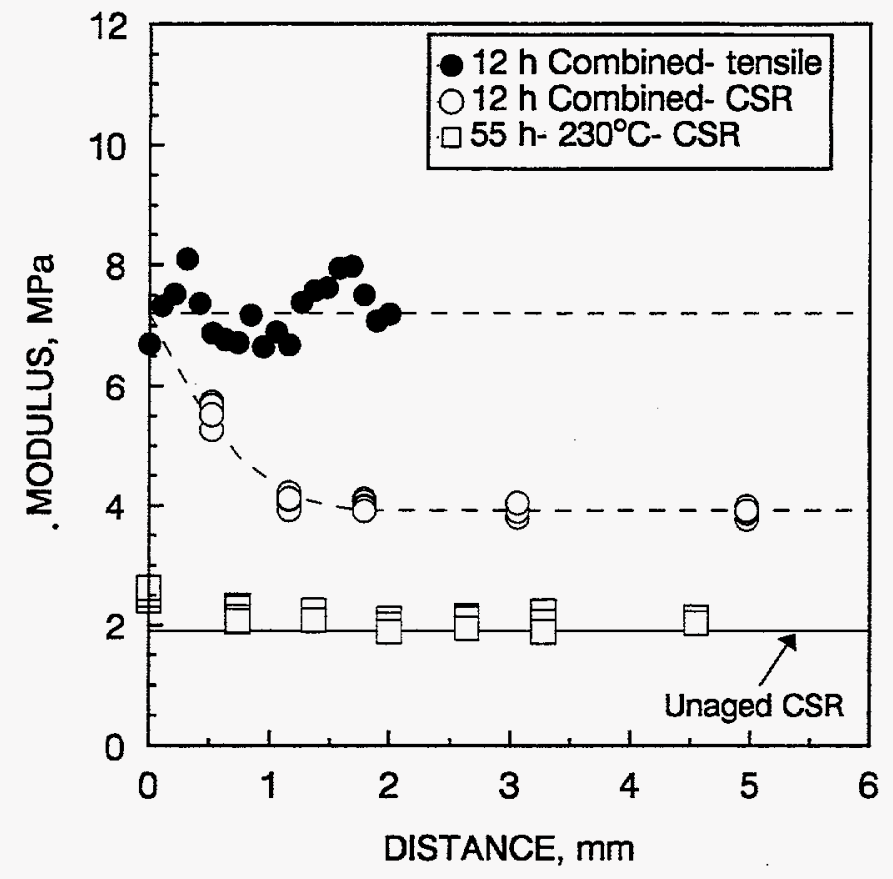

Figure 29. Modulus profile results of CSR and tensile $M$ specimens aged under combined $\left(5.91 \mathrm{kGy} / \mathrm{h}\right.$ plus $\left.230^{\circ} \mathrm{C}\right)$ and $230^{\circ} \mathrm{C}$ thermal-only conditions. The surface of the 29 -mm-diameter CSR samples is at $0 \mathrm{~mm}$.

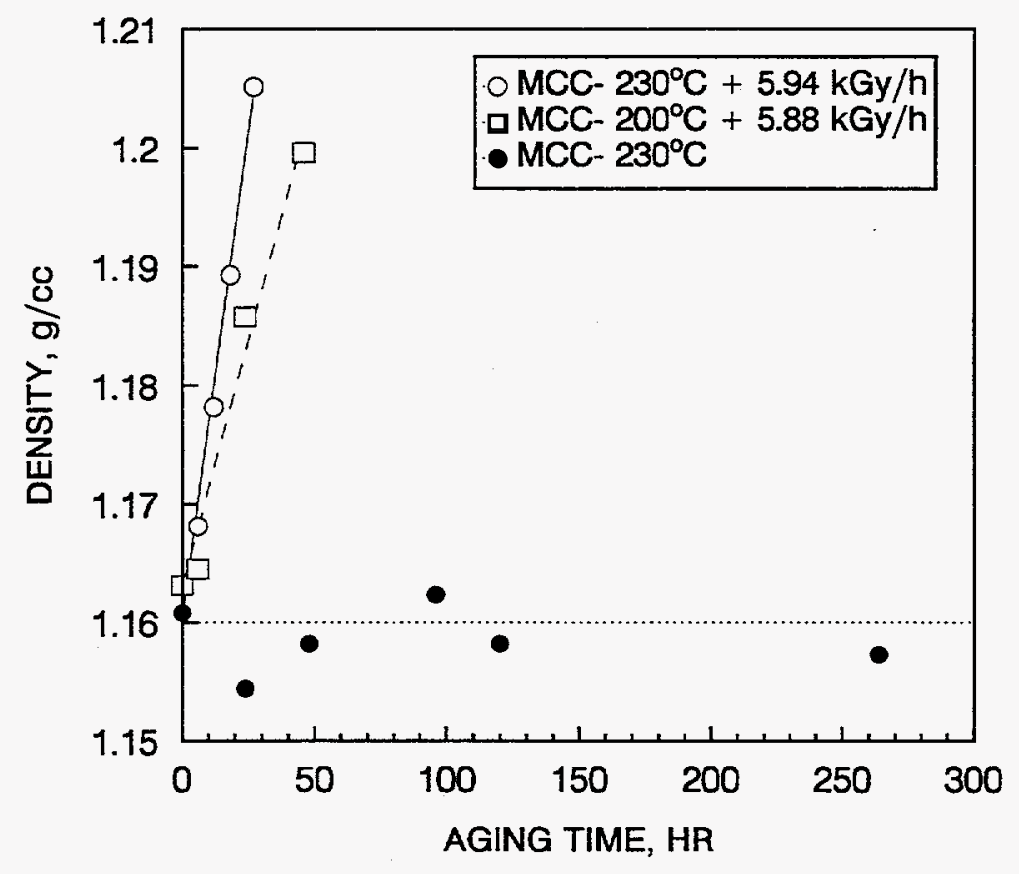

Figure 30. Density results for MCC tensile samples aged under the indicated conditions. 


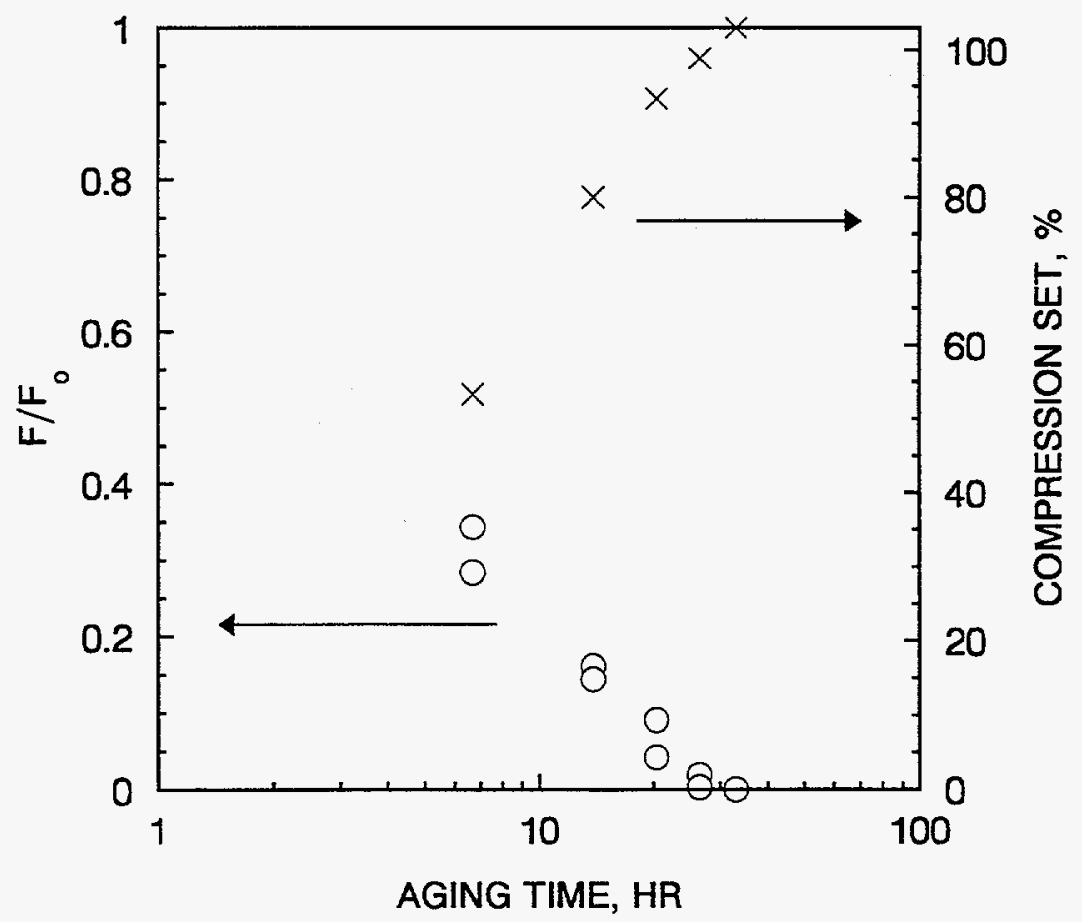

Figure 31. CSR and CS results for the Viton V747 material aged at $230^{\circ} \mathrm{C}$ plus 5.55 $\mathrm{kGy} / \mathrm{h}$. 


\section{APPENDIX A- RAW DATA}

Table A-1. Data used to obtain CSR and CS Results for Experiment C65MCC-1

\begin{tabular}{cccc}
\hline Time, $\mathrm{h}$ & Sample 1-Force, $\mathrm{Nt}$ & Sample 2- Force, $\mathrm{Nt}$ & Sample height, $\mathrm{mm}$ \\
\hline Before Compression & & & 12.55 \\
-18 & 999 & 1039 & \\
-17.9 & 972 & 1009 & \\
0 & 872 & 910 & \\
6 & 250 & 284 & 9.855 \\
12 & 111 & 142 & 9.271 \\
18.33 & 47 & 73 & 9.093 \\
34.83 & 0 & 1 & 8.865 \\
\hline
\end{tabular}

Table A-2. Data used to obtain CSR and CS Results for Experiment C65MCC-2

\begin{tabular}{cccc}
\hline Time, $\mathrm{h}$ & Sample 1-Force, Nt & Sample 2-Force, Nt & Sample height, mm \\
\hline Before Compression & & & 12.56 \\
-17.9 & 1050 & 1132 & \\
-17.8 & 1017 & 1106 & \\
0 & 918 & 986 & \\
27 & 152 & 167 & 9.74 \\
51 & 67 & 81 & 9.21 \\
79 & 35 & 54 & 9.07 \\
\hline
\end{tabular}

Table A-3. Data used to obtain CSR and CS Results for Experiment C65MCC-3

\begin{tabular}{cccc}
\hline Time, $\mathrm{h}$ & Sample 1- Force, Nt & Sample 2- Force, Nt & Sample height, mm \\
\hline Before Compression & & & 12.586 \\
-17.5 & 763 & 736 & \\
-17.2 & 718 & 714 & \\
0 & 657 & 649 & \\
5.917 & 325 & 320 & 11.23 \\
23.78 & 106 & 82 & 9.931 \\
45.88 & 7 & 1 & 9.652 \\
\hline
\end{tabular}


Table A-4. Data used to obtain CSR and CS Results for Experiment C65MCC-4

\begin{tabular}{cccc}
\hline Time, $\mathrm{h}$ & Sample 1-Force, Nt & Sample 2-Force, Nt & Sample height, $\mathrm{mm}$ \\
\hline Before Compression & & & 12.57 \\
-17.4 & 792 & 808 & \\
-17.2 & 769 & 766 & \\
0 & 709 & 696 & \\
6 & 546 & 477 & 12.19 \\
23.2 & 349 & 320 & 11.58 \\
30.2 & 340 & 301 & 11.46 \\
48.37 & 243 & 242 & 10.95 \\
117 & 151 & 138 & 10.21 \\
193.6 & 114 & 113 & 9.96 \\
288.8 & 77 & 88 & 9.80 \\
379.4 & 43 & 58 & 9.70 \\
\hline
\end{tabular}

Table A-5. Data used to obtain CSR and CS Results for Experiment C65MCC-5

\begin{tabular}{cccc}
\hline Time, $\mathrm{h}$ & Sample 1- Force, $\mathrm{Nt}$ & Sample 2-Force, Nt & Sample height, mm \\
\hline Before Compression & & & 12.55 \\
-17.4 & 760 & 774 & \\
-17.2 & 740 & 750 & \\
0 & 680 & 688 & \\
6 & 554 & 508 & 11.43 \\
23.2 & 415 & 385 & 10.52 \\
30.2 & 399 & 355 & 10.39 \\
48.37 & 311 & 310 & 10.13 \\
117 & 167 & 134 & 9.78 \\
193.6 & 107 & 79 & 9.65 \\
288.8 & 58 & 24 & 9.63 \\
379.4 & 9 & 6 & 9.58 \\
\hline
\end{tabular}

Table A-6. Data used to obtain CSR and CS Results for Experiment C65M-1

\begin{tabular}{cccc}
\hline Time, $\mathrm{h}$ & Sample 1-Force, Nt & Sample 2- Force, Nt & Sample height, $\mathrm{mm}$ \\
\hline Before Compression & & & 12.73 \\
-22.5 & 712 & 744 & \\
-22.3 & 683 & 707 & \\
0 & 599 & 620 & \\
6.25 & 102 & 44 & 9.96 \\
12 & 6 & 2 & 9.63 \\
\hline
\end{tabular}


Table A-7. Data used to obtain CSR and CS Results for Experiment C65M-2

\begin{tabular}{|c|c|c|c|}
\hline Time, $\mathrm{h}$ & Sample 1-Force, $\mathrm{Nt}$ & Sample 2-Force, $\mathrm{Nt}$ & Sample height, $\mathrm{mm}$ \\
\hline Before Compression & & & 12.71 \\
\hline-18 & 686 & 721 & \\
\hline-17.8 & 649 & 685 & \\
\hline 0 & 576 & 606 & \\
\hline 5.5 & 222 & 191 & 11.07 \\
\hline 22 & 77 & 45 & 10.01 \\
\hline 38 & 33 & 11 & 9.75 \\
\hline 55.5 & 6 & 4 & 9.65 \\
\hline
\end{tabular}

Table A-8. Data used to obtain CSR and CS Results for Experiment C65M-3

\begin{tabular}{cccc}
\hline Time, $\mathrm{h}$ & Sample 1- Force, $\mathrm{Nt}$ & Sample 2- Force, $\mathrm{Nt}$ & Sample height, $\mathrm{mm}$ \\
\hline Before Compression & & & 12.74 \\
0 & 588 & 581 & \\
6.47 & & 155 & 10.11 \\
13.38 & & 42 & 9.78 \\
19.68 & 8 & 9 & 9.65 \\
25.05 & 2 & 9.60 \\
49 & & & 9.55 \\
\hline
\end{tabular}

Table A-9. Data used to obtain CSR and CS Results for Experiment C65M-4

\begin{tabular}{cccc}
\hline Time, $\mathrm{h}$ & Sample 1- Force, Nt & Sample 2- Force, Nt & Sample height, mm \\
\hline Before Compression & & & 12.73 \\
-48 & 617 & 659 & \\
-47.8 & 589 & 632 & \\
-24 & 526 & 563 & \\
0 & 514 & 549 & \\
5.88 & 308 & 355 & 11.84 \\
11.72 & 245 & 293 & 11.35 \\
29.22 & 164 & 223 & 10.52 \\
48.63 & 123 & 192 & 10.21 \\
72.5 & 81 & 140 & 9.98 \\
97.3 & 55 & 132 & 9.88 \\
122.2 & 37 & 109 & 9.80 \\
189.5 & 14 & 83 & 9.68 \\
260.1 & 3 & 59 & 9.65 \\
\hline
\end{tabular}


Table A-10. Data used to obtain CSR and CS Results for Experiment C65M-5

\begin{tabular}{|c|c|c|c|}
\hline Time, $\mathrm{h}$ & Sample 1-Force, Nt & Sample 2-Force, $\mathrm{Nt}$ & Sample height, $\mathrm{mm}$ \\
\hline Before Compression & & & 12.83 \\
\hline-48 & 714 & 676 & \\
\hline-47.8 & 689 & 651 & \\
\hline-24 & 598 & 561 & \\
\hline 0 & 584 & 545 & \\
\hline 5.88 & 381 & 380 & 10.64 \\
\hline 11.72 & 359 & 334 & 10.46 \\
\hline 29.22 & 312 & 264 & 10.21 \\
\hline 48.63 & 254 & 207 & 9.98 \\
\hline 72.5 & 188 & 150 & 9.88 \\
\hline 97.3 & 167 & 88 & 9.80 \\
\hline 122.2 & 142 & 96 & 9.80 \\
\hline 189.5 & 87 & 67 & 9.70 \\
\hline 260.1 & 35 & 32 & 9.65 \\
\hline
\end{tabular}

Table A-11. Data used to obtain CSR and CS Results for Experiment V747-75-1

\begin{tabular}{cccc}
\hline Time, $h$ & Sample 1- Force, Nt & Sample 2- Force, Nt & Sample height, mm \\
\hline Before Compression & & & 4.42 \\
-17.97 & 361 & 306 & \\
-17.8 & 337 & 291 & \\
0 & 297 & 260 & \\
6.67 & 124 & 87 & 3.81 \\
13.87 & 58 & 44 & 3.51 \\
20.4 & 33 & 13 & 3.35 \\
26.5 & 7 & 1 & 3.29 \\
33 & 0 & 0 & 3.24 \\
\hline
\end{tabular}


Table A-12. Italian CS data (\% set) for Oven Aging of MCC at 20\% Compression

\begin{tabular}{cccccc}
\hline Time, $\mathrm{h}$ & $170^{\circ} \mathrm{C}$ & $180^{\circ} \mathrm{C}$ & $190^{\circ} \mathrm{C}$ & $200^{\circ} \mathrm{C}$ & $220^{\circ} \mathrm{C}$ \\
\hline 4 & & & & & 20 \\
6 & & & 18.6 & & \\
8 & & & & 27.8 & 31.4 \\
16 & & 19.6 & 31.4 & & 40 \\
24 & & & & 51.9 & 46.5 \\
36 & & & & \\
48 & 17.3 & & & & 70.2 \\
60 & & 28.3 & & & \\
72 & & & & & \\
96 & 21.1 & 35.5 & & & \\
120 & & & 61.9 & 79.1 & \\
168 & 33.7 & & & & \\
240 & & 53.8 & 75.2 & 94.2 & \\
336 & 44.9 & & 81.6 & & \\
504 & & 72.1 & & & \\
840 & 63.1 & 78.5 & & & \\
1680 & 84.7 & & & & \\
\hline
\end{tabular}

Table A-13. Italian CS data (\% set) for Oven Aging of $\mathrm{M}$ at 20\% Compression

\begin{tabular}{cccccc}
\hline Time, $\mathrm{h}$ & $170^{\circ} \mathrm{C}$ & $180^{\circ} \mathrm{C}$ & $190^{\circ} \mathrm{C}$ & $200^{\circ} \mathrm{C}$ & $220^{\circ} \mathrm{C}$ \\
\hline 2 & & & & & 6.7 \\
4 & & & & 26.1 & 12.6 \\
6 & & 14 & 20.9 & & \\
8 & 18.7 & & & 32.3 & 26.2 \\
16 & & 23.4 & 32.9 & & \\
24 & 38.6 & & & 64.4 & 78.2 \\
36 & & 49.9 & 64 & & 81.1 \\
48 & 52.7 & & & 82.7 & 86.5 \\
60 & & 60.4 & 76.3 & 83.1 & \\
72 & 63.7 & & & 84.9 & \\
96 & & 75.1 & & & \\
120 & 75.9 & & 88.1 & 96.2 & \\
168 & & 85.1 & & & \\
240 & 84.5 & & 95.2 & & \\
336 & & & 98.6 & & \\
504 & & 96 & & & \\
840 & 96 & & & & \\
\hline
\end{tabular}


Table A-14. MCC tensile elongation data

\begin{tabular}{ccc}
\hline Condition & time, $\mathrm{h}$ & time, $\mathrm{h}$ \\
\hline UNAGED & 0 & $665 \pm 30$ \\
$230^{\circ} \mathrm{C}+5.94 \mathrm{kGy} / \mathrm{h}$ & 6 & $93,88,99$ \\
& 12 & $46,43,25$ \\
$200^{\circ} \mathrm{C}+5.88 \mathrm{kGy} / \mathrm{h}$ & 18.3 & $9,10,13$ \\
& 5.9 & $215,286,269$ \\
& 23.8 & $23,30,22$ \\
$230^{\circ} \mathrm{C}$ & 45.9 & $0,0,0$ \\
& 24 & $372,413.493$ \\
& 48 & $312,365,336$ \\
& 72 & $323,363,315$ \\
& 120 & $281,192,363$ \\
& 264 & $142,220,189$ \\
& 432 & 178 \\
& 600 & 130 \\
& 792 & 102 \\
& 984 & 101 \\
& 1368 & 49 \\
& 5.8 & $695,662,625$ \\
& 11.7 & 602,643 \\
& 29.2 & $592,600,549$ \\
& 96 & $491,403,435$ \\
& 192 & $310,387,431$ \\
& 264 & $251,335,420$ \\
& 384 & $328,345,311$ \\
\hline
\end{tabular}


Table A-15. M tensile elongation data

\begin{tabular}{ccc}
\hline Condition & time, $\mathrm{h}$ & time, $\mathrm{h}$ \\
\hline UNAGED & 0 & $454 \pm 30$ \\
$230^{\circ} \mathrm{C}+5.91 \mathrm{kGy} / \mathrm{h}$ & 6.25 & $80,89,73$ \\
& 12 & $45,35,25$ \\
$200^{\circ} \mathrm{C}+5.71 \mathrm{kGy} / \mathrm{h}$ & 6.3 & $158,168,125$ \\
& 11.5 & $45,59,80$ \\
$230^{\circ} \mathrm{C}$ & 7.7 & $403,321,431$ \\
& 24 & $252,312,288$ \\
& 48 & $206,202,211$ \\
& 72 & $201,248,243$ \\
& 120 & $200.190,210$ \\
& 264 & $90,90,142$ \\
& 432 & 111 \\
& 600 & 102 \\
& 792 & 59 \\
& 984 & 65 \\
& 1368 & 35 \\
& 5.8 & $412,459,420$ \\
& 11.7 & $453,418,402$ \\
& 29.2 & $325,393,363$ \\
& 72 & $315,290,300$ \\
& 96 & 272,315 \\
& 192 & $225,251,206$ \\
& 264 & $200,175,215$ \\
\hline
\end{tabular}




\section{Unclassified Unlimited Release}

DOE

Mr. Duli C. Agarwal U.S. Department of Energy

NE-50

19901 Germantown Road

Germantown, MD 20874

Mr. Sterling M. Franks

U.S. Department of Energy

NE-50

19901 Germantown Rd

Germantown, MD 20874

Mr. Dennis L. Harrison

U.S. Department of Energy

NE-50

19901 Germantown Road

Germantown, MD 20874

Mr. Robert G. Lange

U.S. Department of Energy

NE-40

19901 Germantown Rd

Germantown, MD 20874

Mr. Steven W. Sorrell (5 copies)

U.S. Department of Energy

850 Energy Drive

Idaho Falls, ID 83401

Mr. Charles A. Thompson ( 5 copies)

U.S. Department of Energy

NE-50

19901 Germantown Rd

Germantown, MD 20874

Mr. Paul Wu

U.S. Department of Energy

NS-10

19901 Germantown Road

Germantown, MD 20874

\section{U.S. Industry Groups}

Mr. Phil Richardson

ABB-CE Owners Group

P.O. Box 500

Windsor, $\mathrm{CN} 06095$
Mr. David J. Firth

B\&W Nuclear Technologies - B\&WOG GLRP

3315 Old Forest Road, P.O. Box 10935

Lynchburg, VA 24506-0935

Mr. John E. Hutchinson

Electric Power Research Institute

1300 Harris Boulevard

Charlotte, NC 28262

Mr. Mati Merilo

Electric Power Research Institute

3412 Hillview Ave.

Palo Alto, CA 94304-1935

Ms. Kathy K. Berry

General Electric - BWROG GLRP

175 Curtner Avenue, MC 172

San Jose, CA 95125

Mr. Alexander Marion

Nuclear Energy Institute

1776 I Street NW, Suite 300

Washington, DC 20006-2496

Mr. Doug J. Walters

Nuclear Energy Institute

1776 I Street NW, Suite 300

Washington, DC 20006-2496

Mr. Phil M. Holzman (NUGEQ)

Strategic Technologies \& Resources, Inc.

195 High Street

Winchester, MA 01890

Mr. William Horin (NUGEQ)

Winston \& Strawn

1400 L Street NW

Washington, DC 2005-3502

Mr. Charlie Meyer (WOG)

Westinghouse Electric Company

P.O. Box 355 (WEC 4-22 E)

Pittsburgh, PA 15230

Mr. Roger Newton

WOG GLRP Liaison

Wisconsin Electric Power Co.

P.O. Box 2046

Milwaukee, WI 53021

Mr. James R. Bauman

Institute of Nuclear Power Operations

1100 Circle 75 Parkway, Suite 1500

Atlanta, GA 30339 
International

Dr. Giovanni Piccini

ENEL

Via Italo Panattoni 145

00189 Roma

ITALY

Dr. Paolo Vanini (4 copies)

ENEL-ATN

Viale Regina Margherita 137

00198 Roma

ITALY

E. Penno

CISE

via Reggio Emilia 39

Casalla post. 12081.1

20134 Milano

ITALY

\section{$\underline{\text { Sandia - Internal }}$}

$\begin{array}{ll}\text { MS-0736 } & \text { N. R. Ortiz (6400) } \\ \text { MS-0742 } & \text { C. F. Nelson (6414) (5 copies) } \\ \text { MS-0742 } & \text { J. E. Kelly (6414) } \\ \text { MS-0744 } & \text { M. F. Hessheimer (6403) (5 copies) } \\ \text { MS-1407 } & \text { R. L. Clough (1811) } \\ \text { MS-1407 } & \text { K. T. Gillen (1811) (5 copies) } \\ \text { MS-1407 } & \text { G. M. Malone (1811) } \\ & \\ \text { MS-0619 } & \text { Review \& Approval Desk (12690) } \\ & \text { for DOE/OSTI (2 copies) } \\ \text { MS-0899 } & \text { Technical Library (4916) } \\ & \text { (5 copies) } \\ \text { MS-9018 } & \text { Central Technical Files (8940-2) }\end{array}$

